\title{
Article \\ Promotional Effect of Pd Addition on the Catalytic Activity of Composite Pt-Pd/A1SBA-15- $\beta$ Catalyst for Enhanced n-Heptane Hydroisomerization
}

\author{
Karolina Jaroszewska ${ }^{1, * \mathbb{D}}$, Monika Fedyna ${ }^{2} \mathbb{D}$, Aleksandra Masalska ${ }^{1}$, Rafał Łużny ${ }^{1}$ and Janusz Trawczyński ${ }^{1}$ \\ 1 Department of Fuels Chemistry and Technology, Wrocław University of Science and Technology, \\ 7/9 Gdańska St., PL-50344 Wrocław, Poland; aleksandra.masalska@pwr.edu.pl (A.M.); \\ rafal.luzny@pwr.edu.pl (R.Ł.); janusz.trawczynski@pwr.edu.pl (J.T.) \\ 2 Faculty of Chemistry, Jagiellonian University in Kraków, 2 Gronostajowa St., PL-30387 Kraków, Poland; \\ monika.fedyna@uj.edu.pl \\ * Correspondence: karolina.jaroszewska@pwr.edu.pl; Tel.: +48-71-320-63-02
}

check for updates

Citation: Jaroszewska, K.; Fedyna, M.; Masalska, A.; Łużny, R.;

Trawczyński, J. Promotional Effect of Pd Addition on the Catalytic Activity of Composite Pt-Pd/AlSBA-15- $\beta$ Catalyst for Enhanced $n$-Heptane Hydroisomerization. Catalysts 2021, 11, 377. https://doi.org/10.3390/ catal11030377

Academic Editor:

Wladimir Reschetilowski

Received: 24 February 2021

Accepted: 11 March 2021

Published: 13 March 2021

Publisher's Note: MDPI stays neutral with regard to jurisdictional claims in published maps and institutional affiliations.

Copyright: (c) 2021 by the authors. Licensee MDPI, Basel, Switzerland. This article is an open access article distributed under the terms and conditions of the Creative Commons Attribution (CC BY) license (https:// creativecommons.org/licenses/by/ $4.0 /)$

\begin{abstract}
Hierarchical AlSBA-15-zeolite materials were utilized as a supports for preparing hydroisomerization catalysts. Detailed consideration was given to: (i) the effect of the zeolite type introduced into AlSBA-15-zeolite composites (where zeolite is $\beta$, mordenite or ZSM-5) as well as (ii) the promotion effect of Pd addition. The composites showed higher activity in isomerization as compared to $\mathrm{Pt} / \mathrm{AlSBA}-15$. The enhanced isomerization efficiency were explained by the appropriate metallic and acidic function as well as suitable transport properties. The modification of the hydrogenating function by $\mathrm{Pd}$ incorporation increases the hydroisomerization efficiency of Pt-Pd/AlSBA-15- $\beta$ catalyst. Over bimetallic Pt-Pd/AlSBA-15- $\beta$, the high yields of isomers (68 $\mathrm{wt} \%$ ) with respect to $50 w t \%$ for a control catalyst. The most promising Pt-Pd/AlSBA-15- $\beta$ catalyst allows to improve research octane number from 0 to the 74 value.
\end{abstract}

Keywords: n-alkanes; hydroisomerization; octane number; composite catalysts; AlSBA-15; $\beta$ zeolite

\section{Introduction}

Global environmental concerns and more drastic requirements for advanced vehicle fuels with maximum combustion efficiency and minimum emissions are leading drivers to improve existing processes or to create innovative technologies for their production. In the case of gasoline, the requirements for high-quality fractions include, inter alia low aromatics content together with maintaining a sufficiently high octane number $(\mathrm{ON})$. The US EPA specifications for gasoline require that the aromatics content be as low as $25 \mathrm{vol} \%$ and $\mathrm{ON}$ is set to a minimum value of 95 [1], while the current quality demands in the European Union limit the aromatics content up to $35 \mathrm{vol} \%$ and require $\mathrm{ON}$ to be also at least 95 units [2]. Therefore, in modern refineries, the branched fractions of $C_{4}-C_{6}$ alkanes are used to obtain high ON components what makes it possible to reduce the use of harmful aromatics. The well-known technologies for hydroisomerization of $C_{4}-C_{6}$ fractions are: UOP/Honeywell PENEX ${ }^{\mathrm{TM}}$ [3], Texaco ISO-TEX ${ }^{\mathrm{TM}}$ [4], UOP/Honeywell TIP-SafeCat ${ }^{\mathrm{TM}}$ [5], Shell HYSOMER ${ }^{\mathrm{TM}}$ [6], Mobil/BP ISOFIN ${ }^{\mathrm{TM}}$ [7], UOP/Honeywell PAR-ISOM ${ }^{\mathrm{TM}}$ [6], Axenes IPSORB $^{\mathrm{TM}}$ [8], HEXORB ${ }^{\mathrm{TM}}$ [9].

Fractions containing $n$-alkanes with carbon numbers more than 6 , such as $C_{7}-C_{9}$, are usually present in the feed stream for catalytic reforming and under the reforming conditions they undergo isomerization but also dehydrocyclisation to aromatic compounds. Since the regulations aim to decrease aromatic hydrocarbons, it seems that, as in the case of $\mathrm{C}_{4}-\mathrm{C}_{6}$ alkanes, an alternative is their hydroisomerization to environmentally friendly gasoline high $\mathrm{ON}$ components. There is still no suitable technology for the conversion of $C_{7}-C_{9}$ cuts into branched fractions because of several problems with their effective hydroisomerization. Due to the high reactivity of the $C_{7}-C_{9}$ hydrocarbons, they are prone 
to cracking over the commercial catalysts used in $\mathrm{C}_{4}-\mathrm{C}_{6}$ hydroisomerization. Furthermore, it is required to decrease the process temperature as the equilibria of the isomerization becomes more favourable at low temperature [10]. At high temperature, the tendency to undesirable cracking, at the expense of the isomerization selectivity, is significantly increased [11]. Besides, high reaction temperature favours the formation of carbonaceous deposits which can deactivate the catalyst [12].

Among linear $\mathrm{C}_{7}-\mathrm{C}_{9}$ alkanes, $n$-heptane is a molecule with great interest because its skeletal isomerization can improve ON from 0 to $44-112$ (Figure 1) [13,14]. The ON values of iso-alkanes are higher than that of their linear counterparts and it rises with the degree of branching. Thus, for gasoline, multi-branched alkanes are much more favourable. The hydrocarbons formed in side reactions like: cracking, aromatisation, cyclisation and dehydrogenation are undesirable products. Cracking negatively influences the carbon atoms economy and the obtained products, even though they are displaying in some cases high $\mathrm{ON}$, are too light to be a valuable gasoline components. Whereas aromatisation provides harmful products affecting not only the gasoline "purity" but also the catalyst deactivation because they are precursors of carbonaceous deposits. The unsaturated compounds formed as a result of dehydrogenation are hydrocarbons with low chemical stability and with poor anti-knocking features. Furthermore, cycloalkanes with seven carbons are not the appropriate compounds for composing of high-grade gasoline due to too their low ON. Hence, the investigation challenge in that area is to develop a suitable technology including an effective catalyst for the isomerization of $C_{7}-C_{9}$ into valuable high $\mathrm{ON}$ multibranched isomers running without side reactions. Selective conversion of $\mathrm{C}_{7}-\mathrm{C}_{9}$ linear hydrocarbons into high-quality products along with eliminating by-products and maintaining carbon atom economy would enable the realisation of the hydroisomerization process in line with the idea of green chemistry [15]. Another important aspect that should be taken into account is ensuring a sufficiently high volume of fuels received from renewable sources on the energy market. Thus, if we consider the perspective of obtaining bio- $n$-alkanes with the boiling range of gasoline from natural raw materials $[16,17]$ finding an effective catalyst for isomerization will be an important progress in the production of high-quality biogasoline.

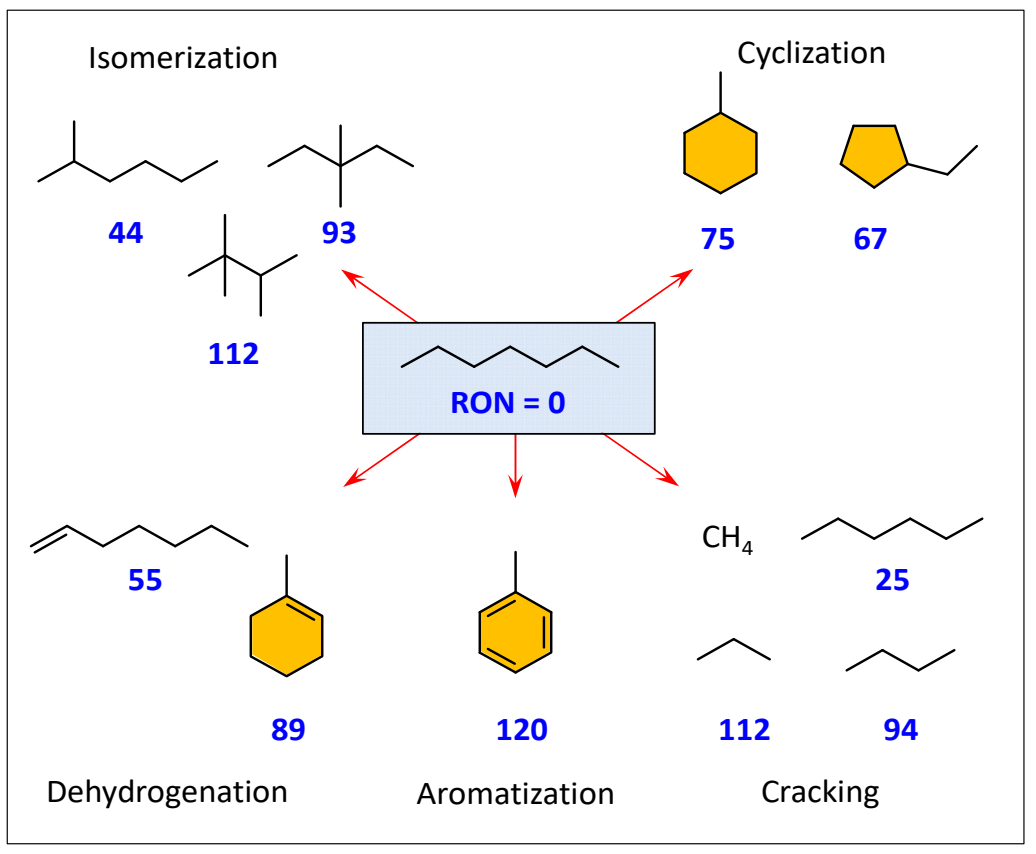

Figure 1. The possible products in the catalytic conversion of n-heptane (there are also Research Octane Number-RON-presented). Isomerization and cyclization products are desired, while dehydrogenation, aromatization, and cracking are undesired. 
It is generally accepted that isomerization of $n$-alkanes takes place on a bifunctional catalyst through a monomolecular mechanism (Figure 2) $[18,19]$. The metal sites generate intermediate olefins via dehydrogenation of the $n$-alkanes. Then, the protonation of the resulting $n$-alkenes on the Brønsted acid sites generates $n$-carbenium ions. The formed $n$-carbenium ions can undergo $\mathrm{C}-\mathrm{C}$ bond rearrangement into iso-carbocations. The isocarbocations can either desorb from the catalyst surface as iso-alkanes via deprotonation on the Brønsted sites followed by hydrogenation on the metal or fall to cracking ( $\beta$-scission). It is worth noting that the iso-alkene intermediates are prone to $\mathrm{C}-\mathrm{C}$ bond cracking, which would severely reduce the yield of desirable iso-alkane products. Therefore, the inhibition of the cracking of iso-alkene intermediates is the most essential principle for the improvement of the hydroisomerization performance.

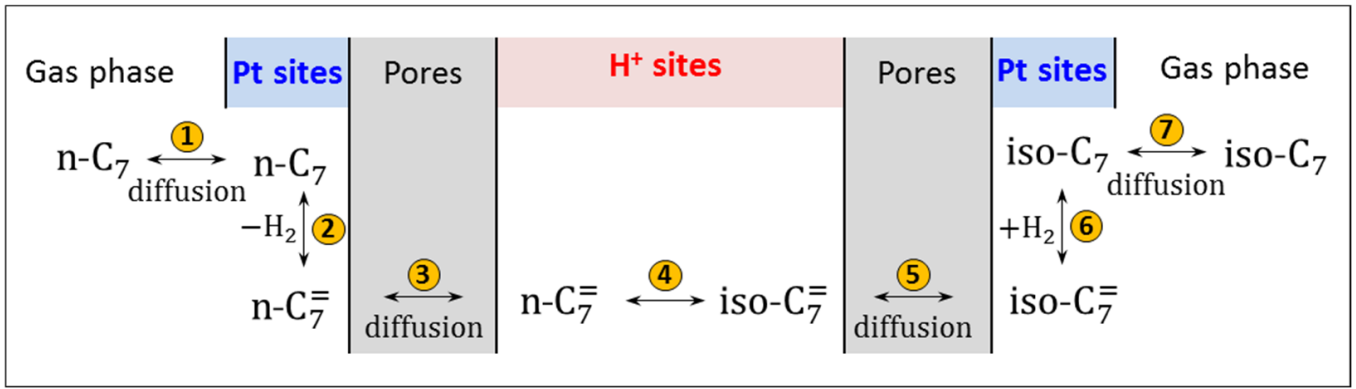

Figure 2. Simplified schematic reaction pathway for the hydroisomerization of $n$-alkanes over bifunctional catalysts; scheme prepared on the basis of $[18,19]$.

It clearly appears that the catalytic performance of the bifunctional catalyst depends strongly on two parameters, i.e., the balance between the metal and Brønsted acid sites (i.e., the ratio of metal to acidic sites and the proximity of both site types) and the diffusion of alkene intermediates in the channels of acidic supports. Therefore, two main approaches are made to enhance the isomerization catalyst efficiency: (i) the selection of active phase composition [20-22] and (ii) the selection of support with appropriate acidity and porous structure [23-25].

In this work, we have investigated the catalytic activities of noble catalysts supported on AISBA-15-zeolite composites for isomerization. It was expected that the unique porous structure of the bimodal AlSBA-15-zeolite composites would provide moderate acidity, improve the accessibility of the active sites, and facilitate overall transport conditions. Whereas, an appropriately selected composition of the metallic phase with high dispersion would provide a sufficient quantity of active sites for alkene generation and for isomerized alkylcarbenium ions hydrogenation [26,27]. As mentioned above, the catalyst for hydroisomerization of $n$-paraffins containing more than 6 carbons should contain the support which is characterised by lower acidity than the catalyst used for the conversion of short-chain $n$-paraffins as the isomerization selectivity decreases with increasing chain length. Zeolites are the most commonly used acidic supports for bifunctional isomerization catalysts, however, there are some problems associated with their application. Because of the small pore diameter of zeolites the restricted access of the large molecules to the active sites exists. The strong acidity of zeolites favours consecutive cracking reactions producing high quantities of low-value gaseous products. Moreover, owing to their high acidity the coke deposition on active sites is a significant phenomenon and in consequence the catalyst needs frequent regeneration. It seems that mesoporous materials/zeolite composites could be an appropriate support for a selective catalyst for hydroisomerization of $n$-alkanes. The micro-mesoporous composites take the advantages of zeolites, which bear moderate acidity, and the advantage of mesoporous materials with improved diffusivity of bulky molecules. The micro-mesoporous catalysts are expected to show improvement in hydroisomerization because of the shortened residence time of the products within the mesopores and as a consequence the reduced secondary reactions (cracking included). The new catalysts will 
also diminish the use of reforming catalysts, i.e., chlorinated platinum/alumina ones. These catalysts are very sensitive to poisons and moreover they cause the environmental pollutions and technical problems with corrosion as they need to be continuously chlorinated to keep an activity. Therefore, the bifunctional Pt catalyst supported on micro-mesoporous materials which does not require continuous chlorination might be an alternative.

The progress that has been made in the past few years in the synthesis of micromesoporous materials is enamours. Nevertheless, the presented results often describe complicated and thus expensive synthesis methods of bimodal zeolite/mesoporous material composites. In our paper, the biporous AISBA-15-zeolite composite material has been obtained by means of a simple method, i.e., via adding zeolite directly into the colloidal precursor of AlSBA-15 phase. It should be noted that there are studies reporting the hydroisomerization of $C_{7}-C_{9}$ fractions over the catalysts supported on biporous composites, e.g., the last works of Gao and coworkers [28,29]. However, to the best of our knowledge, so far no studies have reported the use of AlSBA-15-zeolite composites prepared through the procedure proposed by us for isomerization of $n$-alkanes. In addition, most of the works regarding the catalytic activity of micro-mesoporous catalysts are related to the materials in powder form. Our investigation concerns the catalytic performance of catalysts supported on multicomponent mixtures, i.e., AlSBA-15-zeolite materials extruded with binder (here $\gamma-\mathrm{Al}_{2} \mathrm{O}_{3}$ ). It allows to follow not only the properties of micro-mesoporous catalysts in $n$-alkanes branching but also to test the catalysts which are similar to the commercial ones, i.e., shaped with binder [30]. Studies on the micro-mesoporous materials rather do not take into account that aspect.

The aim of this paper is to evaluate the catalytic activities of noble catalysts supported over shaped with binder AlSBA-15-zeolite composites for $n$-heptane isomerization. Particular consideration was given to (i) the influence of zeolite type (i.e., $\beta$, mordenite or ZSM-5) introduced into AISBA-15-zeolite composite supports as well as (ii) the influence of metallic phase composition (i.e., $\mathrm{Pt}, \mathrm{Pd}$ or $\mathrm{Pt}-\mathrm{Pd}$ ).

\section{Results and Discussion}

\subsection{Catalysts Characterisation}

The evidences for a highly ordered hexagonal structure of AlSBA-15 in supports and catalysts are provided by the low temperature $\mathrm{N}_{2}$ adsorption-desorption, TEM micrographs and XRD diffractograms (Figures S1-S3 and Table S1). It is also crucial to confirm the structure of zeolite in AlSBA-15-zeolite supported catalysts since the synthesis of biporous support relies on AlSBA-15 phase crystallisation in the presence of zeolite particles and in consequence the contact of zeolite particles with the acidic environment takes place. The wide-range XRD diffractograms of Pt-, Pd- and Pt-Pd/SBA-BEA samples confirming the presence of the zeolite structure are shown in Figure S4.

$P y$-IR spectra after desorption of pyridine were collected from the catalysts in order to study the acidity (Figure 3 presents the spectra for Pt/SBA-MFI as an example). The concentration and strength of acid sites on all samples are compiled in Table 1. Acid sites were classified as weak (desorption at $200^{\circ} \mathrm{C}$ ), medium (at $250{ }^{\circ} \mathrm{C}$ ), and strong (at 300 and $350^{\circ} \mathrm{C}$ ). The absorption bands at 1455 and $1623 \mathrm{~cm}^{-1}$ are assigned to pyridine interacting with Lewis acid sites $(P y L)$ [31-33]. The absorption bands at 1545 and $1640 \mathrm{~cm}^{-1}$ correspond to pyridine coordinated to Brønsted acid sites $\left(\mathrm{PyH}^{+}\right)[34,35]$. The peak at the $1490 \mathrm{~cm}^{-1}$ is assigned to the pyridine adsorbed on both $\left(\mathrm{PyH}^{+}\right)$and $(\mathrm{PyL})$ acid sites [36]. The absorption band at approximately $1580 \mathrm{~cm}^{-1}$ is ascribed to physisorbed pyridine [37]. In the investigated catalysts the Lewis acid sites may constitute partially coordinated Al atoms in the extraframework aluminium species and silanol groups from AISBA-15, zeolite, and $\gamma-\mathrm{Al}_{2} \mathrm{O}_{3}$ (a binder), as well as metallic electron acceptor species. Meanwhile, the proton donor sites are generated by framework $\mathrm{Al}$ species in AlSBA-15 and zeolite. 


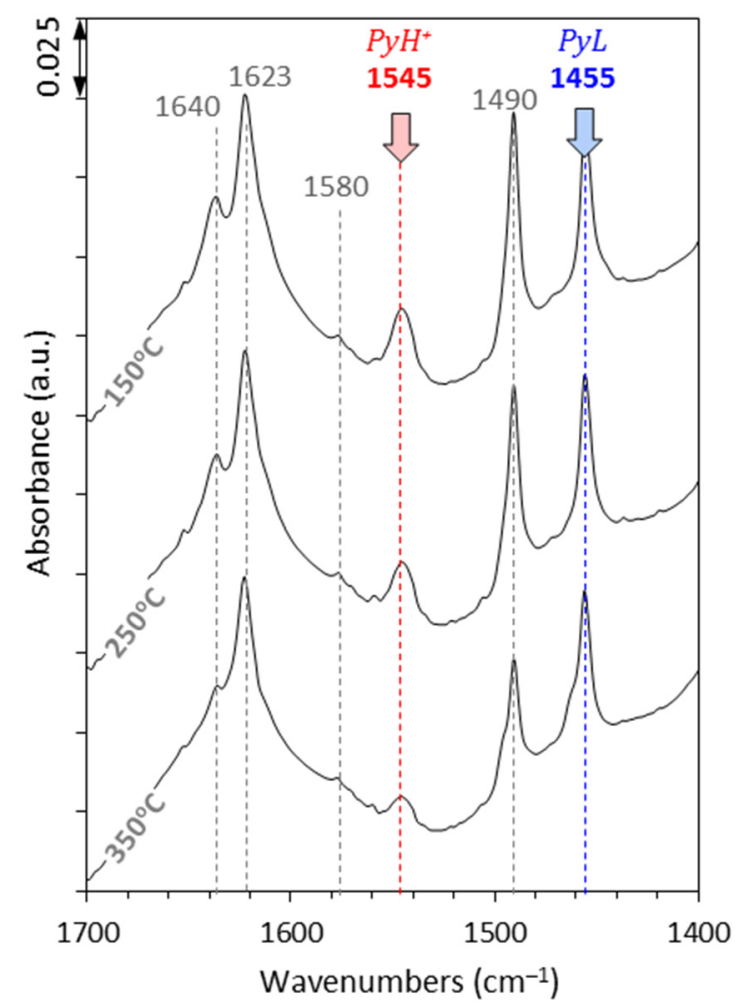

Figure 3. FTIR spectra of pyridine adsorbed on Pt/SBA-MFI catalyst; $P y H^{+}$, Brønsted acid sites; PyL, Lewis acid sites.

Table 1. Acidity of the catalysts by Py-IR.

\begin{tabular}{|c|c|c|c|c|c|c|c|c|c|c|c|}
\hline \multirow{2}{*}{ Catalyst } & \multicolumn{5}{|c|}{$n_{P y H^{+}}{ }^{a}\left(\times 10^{-19} \mathrm{~g}_{\mathrm{cat}}^{-1}\right)$} & \multicolumn{5}{|c|}{$n_{P y L}{ }^{b}\left(\times 10^{-19} \mathrm{~g}_{\text {cat }}^{-1}\right)$} & \multirow{2}{*}{$\begin{array}{c}\sum n_{P y-I R}{ }^{\mathrm{c}} \\
\left(\times 10^{-19} \mathrm{~g}_{\text {cat }}^{-1}\right)\end{array}$} \\
\hline & Total & Weak & Medium & Strong & $\mathbf{A}_{350} / \mathbf{A}_{150}{ }^{\mathrm{d}}$ & Total & Weak & Medium & Strong & $\mathrm{A}_{350} / \mathrm{A}_{150}{ }^{\mathrm{d}}$ & \\
\hline Pt/AlSBA-15 & 3.43 & 0.42 & 1.32 & 1.68 & 0.12 & 5.36 & 0.66 & 0.66 & 4.03 & 0.75 & 8.79 \\
\hline $\mathrm{Pt} / \mathrm{BEA}$ & 15.1 & - & 3.43 & 11.6 & 0.77 & 8.13 & - & - & 8.13 & 1.00 & 23.2 \\
\hline $\mathrm{Pt} / \mathrm{SBA}-\mathrm{BEA}$ & 5.18 & 1.32 & 1.75 & 2.1 & 0.16 & 3.55 & 0.36 & 0.18 & 3.01 & 0.81 & 8.73 \\
\hline $\mathrm{Pt} / \mathrm{SBA}-\mathrm{MOR}$ & 3.85 & - & 0.84 & 3.01 & 0.45 & 4.03 & 0.12 & 0.48 & 3.43 & 0.79 & 7.89 \\
\hline $\mathrm{Pt} / \mathrm{SBA}-\mathrm{MFI}$ & 6.02 & 0.84 & 1.69 & 3.49 & 0.36 & 5.06 & 0.48 & 0.54 & 4.03 & 0.75 & 11.1 \\
\hline $\mathrm{Pd} / \mathrm{SBA}-\mathrm{BEA}$ & 3.85 & 0.42 & 1.26 & 2.16 & 0.23 & 2.65 & 0.36 & 0.12 & 2.17 & 0.82 & 6.50 \\
\hline $\mathrm{Pt}-\mathrm{Pd} / \mathrm{SBA}-\mathrm{BEA}$ & 8.61 & 0.90 & 3.85 & 3.86 & 0.20 & 6.62 & 0.42 & 1.57 & 4.63 & 0.59 & 15.2 \\
\hline
\end{tabular}

${ }^{a}$ Brønsted acid sites; ${ }^{\mathrm{b}}$ Lewis acid sites; ${ }^{\mathrm{c}}$ Total acidity; ${ }^{\mathrm{d}}$ The $\mathrm{A}_{350} / \mathrm{A}_{150}$ ratio, where $\mathrm{A}_{150}$ is the intensity of the Py ion band upon evacuation at $150{ }^{\circ} \mathrm{C}$ and $\mathrm{A}_{350}$ is the intensity of the same band upon desorption at $350{ }^{\circ} \mathrm{C}$, was taken as a measure of the acid strength.

Due to the fact that the $n$-alkane hydroisomerization involves the Brønsted acid sites, the detailed discussion of acidity of the catalysts is devoted to the sites being proton donors. As it was predictable, the presence of zeolite in the Pt/AlSBA-15-zeolite catalysts results in higher concentration of the Brønsted acidic sites when compared to the Pt/AlSBA-15.

And more precisely, the incorporation of MOR, BEA or MFI in $20 \mathrm{wt} \%$ zeolite may bring an approximately 1.1, 1.5, and 1.8-fold increase in Brønsted acid site concentrations, respectively. In the case of isomerization, the excess of number of strong acid sites can enhance $n-C_{7}$ cracking and simultaneously reduce the yield of desired products, whereas the presence of not enough number of strong acid sites will decrease the conversion and finally affect the yield of branched products. As a consequence, the ratio of weak acid to strong acid number for all the catalysts was calculated $\left(\mathrm{A}_{350} / \mathrm{A}_{150}\right)$. Besides, we also consider a number of moderate acid sites as the key factor influencing the catalyst activity.

The Brønsted acid sites are present in all samples and their concentration increases in the following order: $\mathrm{Pt} / \mathrm{SBA}-\mathrm{MOR}<\mathrm{Pt} / \mathrm{SBA}-\mathrm{BEA}<\mathrm{Pt} / \mathrm{SBA}-\mathrm{MFI}$; i.e., it increases with a decrease in $\mathrm{Si} / \mathrm{Al}$ ratio in zeolite added to AlSBA-15. There is also a rise in the strength $\left(\mathrm{A}_{350} / \mathrm{A}_{150}\right)$ of the acid Brønsted sites-in the case of SBA-BEA supported catalyst 
by about $25 \%$ whereas in the case of SBA-MOR and SBA-MFI containing catalysts by about $70 \%$ compared to Pt/AlSBA-15. Acidity determinations also show that the mediumstrength acid sites are predominant in Pt/SBA-BEA catalyst. While the Pt/SBA-MOR and $\mathrm{Pt} / \mathrm{SBA}-\mathrm{MFI}$ catalysts display the highest proportion of acid sites defined as strong.

The acidity measurements have also revealed that the active phase composition in the SBA-BEA supported catalysts has a substantial influence on their final acidity. Considering the increasing acidity of the catalysts supported on SBA-BEA can be arranged in order: $\mathrm{Pd}<\mathrm{Pt}<\mathrm{Pt}-\mathrm{Pd}$. The Pd/SBA-BEA catalyst displays lower acidity than its Pt counterpart and that acidity detraction is observed in respect to the both types of acid sites as well as to their strength. Pt-Pd/SBA-BEA samples exhibit the highest quantity of acidic sites but these sites display a comparable strength of acid sites relative to Pt/SBA-BEA. The incorporation of bimetallic Pt-Pd phase onto the SBA-BEA surface may bring slightly above or slightly below two-fold growth in acidity compared to Pd/SBA-BEA and Pt/SBA-BEA, respectively.

To explain the differences in the catalyst acidity, one may consider many factors influencing their final surface properties [38]. In general, the deposition of metal clusters into the acidic supports induces two opposite effects. Firstly, the introduced metal species could overlay some of the acidic sites originated from the support, bringing about the decrease of both types of acid sites [39]. Secondly, the new Lewis and Brønsted acid sites may also be formed as a result of interactions between the metal precursor and the support during the impregnation procedure. It has been observed by several authors that after Pt incorporation from $\mathrm{H}_{2} \mathrm{PtCl}_{6}$ onto the acidic materials (zeolites and $\mathrm{SiO}_{2} \mathrm{Al}_{2} \mathrm{O}_{3}$ ), Lewis and Brønsted acidity was induced [40-42]. The metal-support interactions were claimed to originate from: (i) the charge transfer between the metal atoms and zeolite oxygen atoms [43] and also the charge transfer between active phase components in bimetallic catalysts [44], (ii) the formation of metal-proton adducts [45,46] as well as from (iii) the effect of "extraneous" ions which were introduced during the synthesis of supports and catalysts [47]:

(i) The redistribution of charge at the metal-support interfacial region is an omnipresent phenomenon in zeolite supported catalysts. The porous materials offer not only a surface to hold and stabilize dispersed metallic phases but may also affect their oxidation state [42]. The charge can be transferred from the metal surface to the oxide support, and conversely, causing the electron-deficient or electron-rich configuration of active sites [48] On acidic supports (e.g., zeolites or AlSBA-15 materials), the positive charge of noble metals can be attributed to a strong interaction between the metal cluster and the acidic hydroxyl groups of the support [49]. The metal species are electron deficient and their electron deficiency increases with the increase in the support acidity. The electron deficient metal crystallites are electron pairs acceptors and they may serve as a kind of new created Lewis acid sites, which recompense the primary Lewis acid sites coming from the support and being covered during impregnation. The almost 2.5-fold higher dispersion of $\mathrm{Pt}$ than $\mathrm{Pd}$ in our catalysts indicates the stronger metal-support interactions in Pt/SBA-BEA catalyst than in Pd counterpart. Therefore, one can expect that over Pt catalyst with the same amount as for Pd one, the number of Lewis sites will be notably greater.

(ii) The formation of positively charged $\left[\mathrm{Pt}_{n}-\mathrm{H}\right]^{+}$and $\left[\mathrm{Pd}_{\mathrm{n}}-\mathrm{H}\right]^{+}$adducts in the catalysts supported over protonic forms of zeolites was proposed to explain the presence of electron deficient particles $[45,50]$. In these complexes the noble metal atoms carry a positive charge, and zeolite protons modify the electronic structure of metal. The adducts are formed between small zeolite-encaged metal particles and zeolite protons. The intimacy between the metal particles and acidic sites promotes electron transfer from metal to acid sites and as a consequence it promotes creation electron-deficient metal clusters [51]. The generation of these metal-proton species is an essential phenomenon since such adducts have been shown to be active sites in isomerization [50]. The adducts are capable of acting as kind of "hybrid sites" (or "collapsed bifunctional sites") combining typical properties of metal 
surfaces with those of Brønsted acids [45,52]. It seems that in our work $\left[\mathrm{Pt}_{\mathrm{n}}-\mathrm{H}\right]^{+}$complexes are more favoured over SBA-BEA support than $\left[\mathrm{Pd}_{\mathrm{n}}-\mathrm{H}\right]^{+}$ones.

(iii) Consideration should also be given to the influence of residual ions from the metal precursor and other ingredients used during the synthesis of catalysts on their final acidity. It seems that chloride ions may play a significant role here. The time-of-flight secondary ion mass spectrometry presented in our earlier study [53] has revealed that the surface of Pt/AlSBA-15 catalysts is covered by chlorine species resulted from incomplete decomposition of $\mathrm{H}_{2} \mathrm{PtCl}_{6}$ or $\mathrm{HCl}$ ( $\mathrm{HCl}$ was incorporated during AlSBA-15 synthesis). The presence of chlorine ions over the surface of $\mathrm{Pt}$ catalysts as a result of impregnation with of $\mathrm{H}_{2} \mathrm{PtCl}_{6}$ has been confirmed by other authors [54,55]. In line with the literature data, the incorporation of $\mathrm{Cl}^{-}$ions onto the various supports, either as part of the $\mathrm{Pt}$ precursor (incomplete decomposition of $\mathrm{H}_{2} \mathrm{PtCl}_{6}$ ) or after chlorination may bring the Brønsted sites to appear [56-58]. Jongpatiwut et al. [59] have observed that halogenation (in his work fluorination) of $\mathrm{Pt}-\mathrm{Pd} / \mathrm{Al}_{2} \mathrm{O}_{3}$ strongly increases the acidity of the catalysts. D'Ippolito et al. [60] have also observed an acidity enhancement in the case of Pd catalysts as an effect of $\mathrm{Cl}^{-}$ions added, either by the Pd chlorinated precursors and/or by the added $\mathrm{HCl}$ during metal impregnation. Hence, the presence of residual chloride ions explains the high acidity of Pt/SBA-BEA catalyst. Whereas as in our work, the Pd/SBA-BEA catalyst is prepared without using of chloride ions containing precursor (i.e., $\mathrm{Pd}\left(\mathrm{NO}_{3}\right)_{2} \times 2 \mathrm{H}_{2} \mathrm{O}$ ) its lower acidity is not unexpected. Moreover, the influence of residual chlorine ions on the $\mathrm{Pt}$ and $\mathrm{Pd}$ catalyst acidity can be explained as being due to the variations in their ionic potential. As the ionic potential of $\mathrm{Pt}(9.0 \mathrm{eV})$ is higher than that of $\mathrm{Pd}(8.34 \mathrm{eV})$, it seems that ions of opposite charge, like $\mathrm{Cl}^{-}$, are stronger attracted to $\mathrm{Pt}$ species than to $\mathrm{Pd}$ ones.

The discussion above clarifies the greater acidity of Pt/SBA-BEA compared to Pd/SBABEA catalyst. However, the results of acidity measurements also demonstrate the presence of an additional effect from the bimetallic combination of Pt-Pd upon the simultaneous impregnation with both metallic precursors. Therefore what is the reason of the highest acidity of Pt-Pd/SBA-BEA? We believe that the answer can be found in the interaction not only between $\mathrm{Pt}$-support and $\mathrm{Pd}$-support but also within active phase components, i.e., between Pt and Pd clusters. The electronic effects were claimed to originate from the formation of electron-deficient $\mathrm{Pt}$ species in the bimetallic Pt-Pd particles [61]. However, the precise explanation for the changes in the acidity of Pt-Pd modified catalysts is probably more complicated. We are aware that the discussion needs to be supported by advanced measurements to provide more convincing evidences for the interactions of the active phase with AlSBA-15-zeolite support and vice versa and these between the active phase components in the case of bimetallic catalyst (Pt-Pd). The effect attributed to interactions within Pt-Pd/AlSBA-15-zeolite catalysts is interesting and we think that it is worth to present in separate paper in the future. Nevertheless, the modification of the composition of active phase reflected in the modified acidic and metallic functions is responsible for variations in the catalytic activity of the SBA-BEA supported catalysts as discussed below (Section 2.2.).

Table 2 summarizes the results of CO chemisorption. In the case of AlSBA-15-zeolite supported catalysts, the dispersion of $\mathrm{Pt}$, was found to increase from 34 on a SBA-MFI support, to 48 and $58 \%$ on SBA-MOR and SBA-BEA, respectively. This trend follows the same one as the $\mathrm{S}_{\mathrm{BET}}$ variation among samples. It could suggest that the high $\mathrm{S}_{\mathrm{BET}}$ tends to promote $\mathrm{Pt}$ dispersion. Nevertheless, the measurements show that the $\mathrm{Pt}$ dispersion on $\mathrm{Pt} / \mathrm{AlSBA}-15$, despite its larger surface, is quite lower compared to the Pt/BEA sample. Also, the Pt dispersion on the biporous samples is lower than the dispersion on the BEA supported sample. The interaction between metal and the support components should be also taken into account in the clarification of variations between Pt dispersion in AlSBA-15, AlSBA-15-zeolite, and BEA zeolite alone supported catalysts. It has been found [49] that in the case of Pt/ZSM-5 catalyst a Pt atoms interact with a Brønsted proton and with a nearby bridging framework oxygen. The authors claimed that without the Brønsted acid sites the $\mathrm{Pt}$ atoms are not stable in zeolite and so agglomeration of $\mathrm{Pt}$ atoms to form 
a larger particle is expected. Therefore, the highest of number of Brønsted acid sites in $\mathrm{Pt} / \mathrm{BEA}$ catalyst is responsible for the high dispersion of Pt over the zeolite. The AISBA-15 material, due its high surface area, was expected to provide good spreading of active phase. Nevertheless, the poorer Brønsted acidity in Pt/AlSBA-15 catalyst contributes to lowering the Pt dispersion.

Table 2. Characterization of metal function of the catalysts.

\begin{tabular}{|c|c|c|c|c|c|}
\hline Catalyst & $\begin{array}{l}D^{a} \\
(\%)\end{array}$ & $\begin{array}{c}S_{M}{ }^{b} \\
\left(\mathrm{~m}^{2} \mathrm{~g}_{M}^{-1}\right)\end{array}$ & $\begin{array}{l}d_{M}{ }^{c} \\
(\mathrm{~nm})\end{array}$ & $\begin{array}{c}n_{M} \mathrm{~d} \\
\left(10^{-19} g^{-1}\right)\end{array}$ & $\begin{array}{c}n_{M_{A} A} \mathrm{e}^{-1} \\
\left(\mathbf{1 0}^{-19} \mathrm{~g}^{-1}\right)\end{array}$ \\
\hline Pt/AlSBA-15 & 57 & 142 & 2.0 & 1.54 & 0.88 \\
\hline $\mathrm{Pt} / \mathrm{BEA}$ & 75 & 205 & 1.4 & 1.54 & 1.16 \\
\hline $\mathrm{Pt} / \mathrm{SBA}-\mathrm{BEA}$ & 58 & 144 & 2.0 & 1.54 & 0.90 \\
\hline $\mathrm{Pt} / \mathrm{SBA}-\mathrm{MOR}$ & 48 & 120 & 2.3 & 1.54 & 0.74 \\
\hline $\mathrm{Pt} / \mathrm{SBA}-\mathrm{MFI}$ & 34 & 93 & 3.0 & 1.54 & 0.53 \\
\hline $\mathrm{Pd} / \mathrm{SBA}-\mathrm{BEA}$ & 25 & 63 & 3.7 & 1.54 & 0.39 \\
\hline $\mathrm{Pt}-\mathrm{Pd} / \mathrm{SBA}-\mathrm{BEA}$ & 36 & 95 & 2.7 & 1.54 & 0.56 \\
\hline
\end{tabular}

Note: ${ }^{\mathrm{a}} D$, dispersion; ${ }^{\mathrm{b}} S_{M}$, metal surface; ${ }^{\mathrm{c}} d_{M}$, metal particle size; ${ }^{\mathrm{d}} n_{M}$, number of metal atoms; ${ }^{\mathrm{e}} n_{M}{ }_{A}$ number of accessible metal atoms.

There are also significant differences in active phase dispersion in $\mathrm{Pt}, \mathrm{Pd}$, and $\mathrm{Pt}$ Pd/SBA-BEA catalysts. And as can be seen (Table 2), the metallic phase dispersion in $\mathrm{Pd} / \mathrm{SBA}-\mathrm{BEA}$ and Pt-Pd/SBA-BEA catalysts is lower than that of Pt/SBA-BEA catalyst, even though the same support was used. The lowering of active phase dispersion upon $\mathrm{Pd}$ incorporation into Pt-Pd/ $\beta$ catalysts has been observed by Lee et al. [62]. The reasons should be sought in the interaction between the active phase precursor and the support surface. It is well-known that the active phase dispersion is strongly dependent on the point of zero charge ( $\mathrm{pH}_{\mathrm{PZC}}$ ) of the support, i.e., $\mathrm{pH}$ at which its surface remains neutral. And, considering the purely electrostatic nature of adsorption, the impregnation with a solution with $\mathrm{pH}$ above the $\mathrm{pHpzc}$ value of the support, its surface is negatively-polarised and adsorbs cations [63]. If the solution $\mathrm{pH}$ is below the $\mathrm{pH}_{\mathrm{PZC}}$, the opposite phenomenon takes place; the surface is positively charged and anionic species are adsorbed on it. For AlSBA-15 and $\mathrm{BEA}, \mathrm{pH}_{\mathrm{PZC}}$ is reported to be about 5 [64] and 6, respectively [65]. Thus, due to the protonation of AlSBA-15 and BEA surface at the conditions of using impregnating solution of $\mathrm{H}_{2} \mathrm{PtCl}_{6}$ with $\mathrm{pH}$ amounting 2, the $\left[\mathrm{PtCl}_{6}\right]^{2-}$ anions are attracted to the surface of both supports. However it seems that the Pt anions are preferably adsorbed on the BEA surface, due to the slightly higher $\mathrm{pH}_{\mathrm{PZC}}$ value. Stronger interactions of the Pt species with BEA can, thus, cause a higher Pt dispersion on its surface. In the case of Pd containing samples, this effect could be interpreted in terms of electrostatic attraction or repulsion between $\left[\mathrm{PtCl}_{6}\right]^{2-}$ or $\mathrm{Pd}^{2+}$ ions and the surface of supports components, respectively. In the present study, the investigated catalysts are supported over multicomponent bodies, i.e., consisting of AlSBA-15 ( $\left.\mathrm{pH}_{\mathrm{PZC}} \cong 5\right)$, BEA zeolite $\left(\mathrm{pH}_{\mathrm{PZC}} \cong 6\right)$ and $\mathrm{Al}_{2} \mathrm{O}_{3}\left(\mathrm{pH}_{\mathrm{PZC}} \cong 8\right)$. Thus, at the $\mathrm{pH}$ of impregnating solution of $\mathrm{Pd}\left(\mathrm{NO}_{3}\right)_{2}$, amounting 3.3 and being below that of support $\mathrm{pH}_{\mathrm{PZC}}$, the surface is charged positively and $\mathrm{Pd}^{2+}$ ions are repulsed from the surface of the support components. This results in no uniform Pd species repartition and its low dispersion. Whereas, a positively charged surface of the support during impregnation with $\mathrm{H}_{2} \mathrm{PtCl}_{6}$ solution (with a $\mathrm{pH}$ of 2 being also below the $\mathrm{pH}_{\mathrm{PZC}}$ of the support components) causes $\left[\mathrm{PtCl}_{6}\right]^{2-}$ anions to be attracted to the support surface. In consequence, it can be expected that the dispersion of Pt species on AlSBA-15-zeolite will be higher than Pd ones.

\subsection{Effect of the Type of Zeolite Incorporated to Pt/AlSBA-15-Zeolite}

The catalytic activities of the investigated Pt/AlSBA-15-zeolite catalysts in $n$-heptane conversion are summarized in Table 3 and plotted in Figure 4. For comparison purposes, the results for Pt/AlSBA-15 and Pt/zeolite are also presented in Table 3 and Figure S5, respectively. The results clearly illustrate that the modification of AlSBA-15 with zeolite exerts a noticeable influence on the catalytic properties of corresponding materials. As 
expected, the catalysts supported on AlSBA-15-zeolite exhibit a higher catalytic activity than those based on AlSBA-15, i.e., to obtain the $50 \%$ conversion of $n-C_{7}$ over Pt/AlSBA-15 a temperature of $330{ }^{\circ} \mathrm{C}$ is needed while over Pt/AlSBA-15-zeolite this conversion is achieved at $270{ }^{\circ} \mathrm{C}$ over SBA-BEA and SBA-MOR supported catalysts and at $250^{\circ} \mathrm{C}$ over SBA-MFI based one (Figure 4).
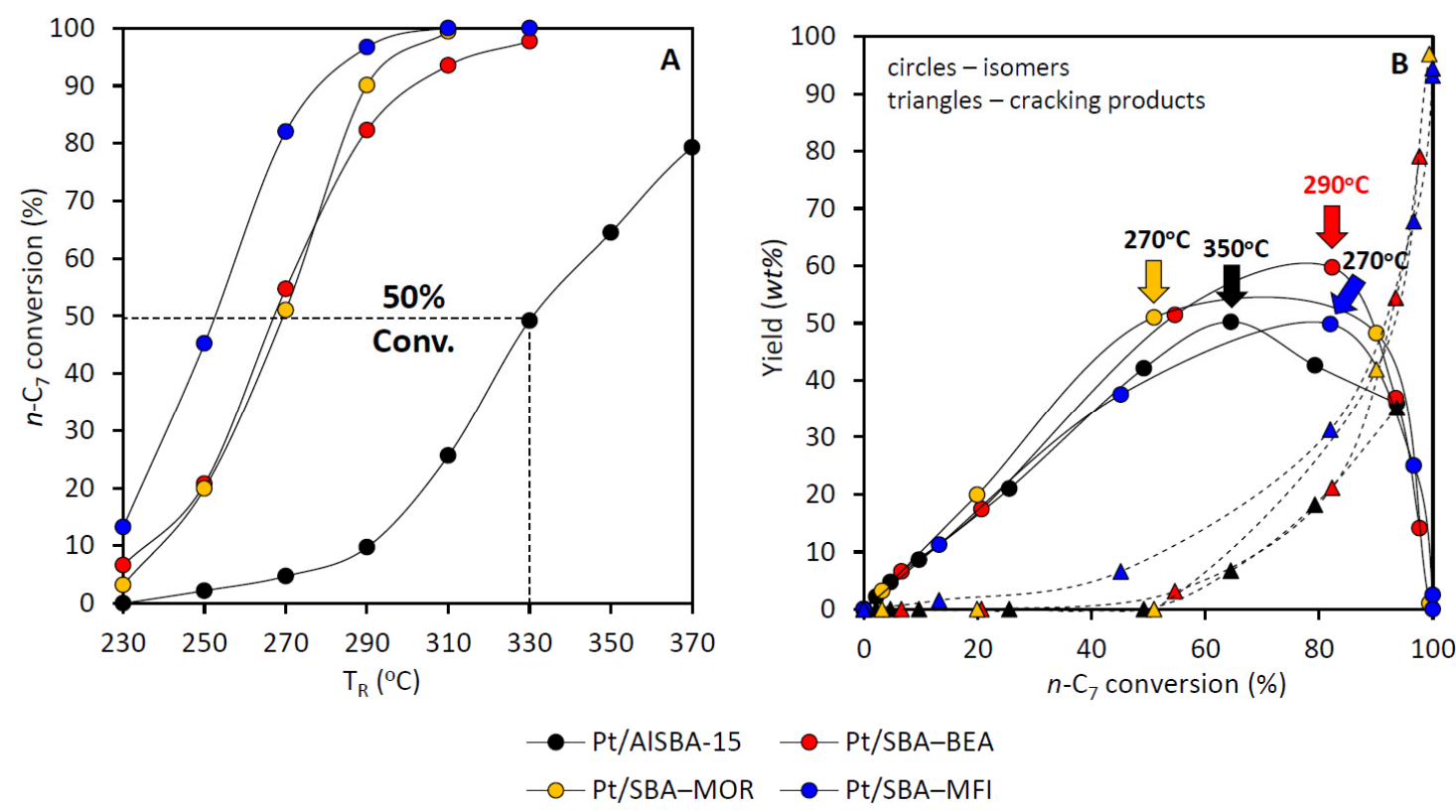

Figure 4. Catalytic performance of the Pt/AlSBA-15 and Pt/AlSBA-15-zeolite catalysts: $(\mathbf{A}) n-\mathrm{C}_{7}$ conversion profiles against $\mathrm{T}_{\mathrm{R}}$ and (B) yield of isomers and cracking products against $n-\mathrm{C}_{7}$ conversion for the corresponding catalysts.

This finding is substantiated by the catalyst acidity measurements (Table 1), which proved the higher concentration of Brønsted acid sites over Pt/AlSBA-15-zeolite samples than over the Pt/AlSBA-15 one. In addition, the zeolite type in AlSBA-15-zeolite support substantially influences the $n-C_{7}$ conversion and the highest conversion (at comparable $T_{R}$ ) is achieved over the $\mathrm{Pt} / \mathrm{SBA}-\mathrm{MFI}$ catalyst (Figure $4 \mathrm{~A}$ ). These results are supported by the apparent activation energies $\left(E_{a}^{a p p}\right)$ calculated for $n$-heptane hydroconversion (Figure S6). The value of $E_{a}^{a p p}$ is equal to $155.2 \mathrm{~kJ} \mathrm{~mol}^{-1}$ for the Pt/AlSBA- 15 catalyst and it is in agreement with the work of Harmel et al. [66]. The $E_{a}^{a p p}$ of $n-C_{7}$ hydroconversion for $\mathrm{Pt} / \mathrm{SBA}-\mathrm{BEA}$ catalyst is found to be approx. equal to the value calculated for Pt/AlSBA-15 one $\left(E_{a}^{a p p}=149 \mathrm{~kJ} \mathrm{~mol}^{-1}\right)$. Modification of the AISBA-15 support with the MOR and MFI zeolites brings the increase in the apparent activation energy up to 186 and $209 \mathrm{~kJ} \mathrm{~mol}^{-1}$, respectively.

It is obvious that Pt catalysts supported only on zeolites (Figure S5) exhibit higher catalytic activity than these based on AlSBA-15-zeolite. The conversion over Pt/zeolite catalysts (at the same $\mathrm{T}_{\mathrm{R}}$ ) is higher by approximately $50 \%$ as compared to the Pt/AlSBA-15zeolite counterparts. However, the product distribution has revealed that over all $\mathrm{Pt} /$ zeolite catalysts the improved conversion is concomitant with the growth in cracking products. $\mathrm{Pt} / \mathrm{MFI}$ and $\mathrm{Pt} / \mathrm{MOR}$ catalysts provide higher yield of $\mathrm{C}_{3}+\mathrm{C}_{4}$ fraction (amounting to 47 and $34 \mathrm{wt} \%$, respectively) than Pt/BEA one (the yield of cracking products amounts to $8.1 \mathrm{wt} \%$ ). The activity enhancement and high activity in the cracking of $\mathrm{Pt} /$ zeolite catalysts relative to AlSBA-15 and AlSBA-15-zeolite supported ones is due to their extensive Brønsted acidity, but mainly to the diffusion limitation within the channels of MOR and MFI structures [67]. Therefore, the Pt/zeolite catalysts display high activity but mainly as a result of high activity in the cracking reaction. It was reported that [68-71] that the channels of MOR and especially MFI framework are insufficiently large to enable the production of isomers. The paraffinic intermediates may have longer life time on acid sites and they 
undergo successive rearrangement and cracking to a large extent because it is difficult for them to leave the pores of the zeolite channels.

Let us to consider the detailed differences in the hydroisomerization performance between the Pt/AISBA-15-zeolite composites and Pt/AlSBA-15 one (Table 3). With Pt/AlSBA15 catalyst, the conversion of $n-C_{7}$ up to $350{ }^{\circ} \mathrm{C}$ primarily leads to the formation of hydroisomerization products; at $350{ }^{\circ} \mathrm{C}$ the iso- $\mathrm{C}_{7}$ yield is the highest and it equals to approx. $52 \mathrm{wt} \%$. It can be observed that the highest yield of iso- $\mathrm{C}_{7}$ on the composite catalysts (regardless of the type of zeolite that was introduced) is achieved at lower $T_{R}$ than on $\mathrm{Pt} / \mathrm{AlSBA}-15$ catalyst (Figure 4B). In the case of Pt/SBA-MOR and Pt/SBA-MFI catalysts, the maximal yield of iso- $\mathrm{C}_{7}$ isomers (ca. $50 \mathrm{wt} \%$ ) is registered at $270{ }^{\circ} \mathrm{C}$ while for $\mathrm{Pt} / \mathrm{SBA}-\mathrm{BEA}$ one it is reached at $290{ }^{\circ} \mathrm{C}(59.7 \mathrm{wt} \%$ ) (Figure 4B). One of the criteria in the evaluation of the catalyst performance in $n-\mathrm{C}_{7}$ hydroisomerization is their efficiency in the production of mono-branched iso- $\mathrm{C}_{7}$ isomers $\left(\mathrm{MoBC}_{7}\right)$ and the most desirable high octane multi-branched iso- $\mathrm{C}_{7}$ ones $\left(\mathrm{MuBC}_{7}\right)$. As it can be inferred from Table 3, almost in all cases the yield of $\mathrm{MoBC}_{7}$ is higher than $\mathrm{MuBC}_{7}$. The $\mathrm{MoBC}_{7}$ fraction includes 2methylhexane $\left(2-\mathrm{MeC}_{6}\right)$, 3-methylhexane $\left(3-\mathrm{MeC}_{6}\right)$, and 3-ethylpentane $\left(3-\mathrm{EtC}_{5}\right) .3-\mathrm{MeC}_{6}$ is slightly favoured against $2-\mathrm{MeC}_{6}$ (see $2-\mathrm{MeC}_{6} / 3-\mathrm{MeC}_{6}$ ratio), especially with the composite catalysts, which can be recognized as the weaker diffusion restriction [72,73].

Table 3. Performance of composite Pt(Pd)/AISBA-15 + zeolite (BEA, MOR or MFI) catalysts in the hydroconversion of $n-\mathrm{C}_{7}$.

\begin{tabular}{|c|c|c|c|c|c|c|c|c|}
\hline \multirow[t]{2}{*}{ Catalyst } & \multirow{2}{*}{$\mathrm{T}_{\mathrm{R}}\left({ }^{\circ} \mathrm{C}\right)$} & \multirow{2}{*}{ Conv. (\%) } & \multicolumn{4}{|c|}{ Hydroisomerization (wt\%) } & \multirow{2}{*}{$\begin{array}{c}\begin{array}{c}\text { Hydrocracking } \\
(\mathbf{w t} \%)\end{array} \\
\mathrm{C}_{3}+\mathrm{C}_{4}\end{array}$} & \multirow{2}{*}{$\begin{array}{c}\begin{array}{c}\text { Dehydrocyclization } \\
(\mathbf{w t} \%)\end{array} \\
\text { Aro \& Cyc }\end{array}$} \\
\hline & & & Total iso- $\mathrm{C}_{7}$ & $\mathrm{MoBC}_{7}{ }^{\mathrm{a}}$ & $\mathrm{MuBC}_{7} \mathrm{~b}$ & $2-\mathrm{MeC}_{6} / 3-\mathrm{MeC}_{6}$ & & \\
\hline Pt/AlSBA-15 & 350 & 64.5 & 50.2 & 44.0 & 6.1 & 0.92 & 6.7 & 7.7 \\
\hline $\mathrm{Pt} / \mathrm{BEA}$ & $270^{c}$ & 72.0 & 63.9 & 49.2 & 14.7 & 0.86 & 8.1 & - \\
\hline $\mathrm{Pt} / \mathrm{MOR}$ & 250 & 90.6 & 56.4 & 30.1 & 26.4 & 0.83 & 34.2 & - \\
\hline $\mathrm{Pt} / \mathrm{MFI}$ & 250 & 99.5 & 52.1 & 27.6 & 24.5 & 0.94 & 47.4 & - \\
\hline $\mathrm{Pt} / \mathrm{SBA}-\mathrm{BEA}^{\mathrm{c}}$ & 290 & 82.3 & 59.7 & 42.7 & 16.9 & 0.83 & 21.1 & 1.5 \\
\hline $\mathrm{Pt} / \mathrm{SBA}-\mathrm{MOR}$ & 290 & 90.1 & 48.2 & 30.1 & 18.1 & 0.76 & 41.9 & - \\
\hline $\mathrm{Pt} / \mathrm{SBA}-\mathrm{MFI}$ & 290 & 96.7 & 25.0 & 15.5 & 9.5 & 0.83 & 67.5 & 1.5 \\
\hline $\mathrm{Pd} / \mathrm{SBA}-\mathrm{BEA}$ & 290 & 48.3 & 38.8 & 30.6 & 8.2 & 0.82 & 9.5 & 0.2 \\
\hline $\mathrm{PtPd} / \mathrm{SBA}-\mathrm{BEA}$ & 290 & 78.1 & 68.2 & 47.5 & 20.7 & 0.80 & 9.9 & 1.5 \\
\hline
\end{tabular}

${ }^{\mathrm{a}} \mathrm{MoBC}_{7}$, monobranched heptane isomers: 2-methylhexane, 3-methylhexane and 3-ethylpentane. ${ }^{\mathrm{b}} \mathrm{MuBC}_{7}$, multibranched heptane isomers: 2,2-dimethylpentane, 2,3-dimethylpentane, 2,4-dimethylpentane, 3,3-dimethylpentane and 2,2,3-trimethylbutane. ${ }^{\mathrm{C}}$ In the case of $\mathrm{Pt} / \mathrm{BEA}$ catalyst, the $270{ }^{\circ} \mathrm{C}$ temperature was presented instead of $250{ }^{\circ} \mathrm{C}$ due to the fact that that catalyst achieved comparable conversion as $\mathrm{Pt} / \mathrm{MOR}$ and $\mathrm{Pt} / \mathrm{MFI}$ at higher by $20^{\circ} \mathrm{C}$, i.e., at $270{ }^{\circ} \mathrm{C}$.

The results (Table 3) have revealed that among the Pt composite catalysts, the Pt/SBA$B E A$ shows the highest efficiency in iso- $C_{7}$ products with relatively high contribution of $\mathrm{MuBC}_{7}$. The Pt/SBA-BEA catalyst provides almost the same iso- $\mathrm{C}_{7}$ yield as $\mathrm{Pt} / \mathrm{BEA}$, and in addition over the previous one the contribution of $\mathrm{MuBC}_{7}$ derivatives is even slightly higher. The Pt/SBA-BEA catalyst gives the highest yield of iso- $\mathrm{C}_{7}$ with the highest contribution of $\mathrm{MuBC}_{7}$ alkanes and small loss of carbon in cracking products (yield of $\mathrm{C}_{3}+\mathrm{C}_{4}$ equals $21 \mathrm{wt} \%$ ). In the case of the two other composite catalysts (i.e., Pt/SBAMOR and Pt/SBA-MFI), the catalytic performance depends on the zeolite type that was introduced. Although the modification of AlSBA-15 with MOR brings a small increase in the $\mathrm{MuBC}_{7}$, there is a notable rise in cracking products (up to $42 \mathrm{wt} \%$ ). While on the Pt/SBA-MFI catalyst, the cracking products are predominant $(67.5 \mathrm{wt} \%)$. It seems that the differences in hydroisomerization performance of AlSBA15-zeolite catalysts are affected by factors previously described for catalysts supported on zeolites alone. In the case of the introduction of BEA, the obtained Pt/SBA-BEA catalyst does not exhibit diffusion restrictions. The increased residence time of the products in the pores of MOR and MFI components of AlSBA-15-zeolite composites maximizes secondary reactions, such as cracking, reducing the selectivity to isomers. The enhancement of hydroisomerization efficiency of Pt/SBA-BEA catalyst can be attributed not only to its porous structure but also to its moderate acidity (Table 1 ).

Over all catalysts tested, the only hydrocracking products are propane and iso-butane what proves that the conversion of $n-C_{7}$ runs in accordance to the classical bifunctional 
monomolecular mechanism, i.e., mainly through $\beta$-scission of 2,2-- $\mathrm{DMeC}_{5}$ and 2,4-DMeC and not through direct cracking of $n-C_{7}$. In the reaction products, no methane or ethane are detected. Methane and ethane are very likely produced through hydrogenolysis, i.e., by cracking on metal sites (either over monofunctional metal catalysts or over metal sites nonwell balanced by acid function in bifunctional catalysts). With the bifunctional metal/acid catalysts, the production of $C_{1}-C_{2}$ hydrocarbons would involve the formation of nonstable primary carbenium ions, therefore the classical monomolecular mechanism does not account for the light hydrocarbons production. Nevertheless, over the monofunctional acid catalyst or bifunctional catalyst with a poor hydrogenating function, $C_{1}-C_{2}$ together with $\mathrm{H}_{2}$ may be formed when the conversion of the alkanes occurs via a non-classical, penta-coordinated carbonium ion (i.e., via the monomolecular reaction mechanism which is preferred under low conversion and at high $T_{R}$ ). Therefore, we conclude that in our work, the absence of light hydrocarbons indicates that the metal/acid function in the examined catalysts is well balanced. It is also worth noticing that the lack of high molecular compounds in the product clearly indicates that the reaction does not run via the dimerisation-cracking mechanism.

The comparison of catalytic performance of Pt/SBA-BEA and Pt/AlSBA- 15 in $n-\mathrm{C}_{7}$ hydroisomerization indicates that the promoting effect of BEA component in Pt/SBA-BEA is evident. The application of a relatively small portion of BEA (i.e., $20 \mathrm{wt} \%$ ) in Pt/SBABEA yields the catalyst displaying an improved performance in isomerization as compared to Pt/A1SBA-15 catalyst. The Pt/SBA-BEA composite catalyst gives a higher amount of isomerization product together with the higher contribution of the most desired $\mathrm{MuBC}_{7}$.

The catalytic properties of Pt/SBA-BEA are explained by not only its moderate acidity and satisfactory Pt dispersion ensuring the appropriate metal/acidity balance but also by the structure of the composite support. The bifunctional catalyst performance in alkanes isomerization depends on the character of its metallic and acidic functions, as well as on their balance, only if there are no diffusive restrictions. When the catalyst contains zeolites, the catalytic performance is also influenced by the geometry and dimensionality of the zeolite channels, i.e., shape-selectivity phenomenon. In the work of Kinger et al. [74], it has been proved that the fast diffusion of the isomers out of the zeolite pores in composites of Pt/MCM-22 + MCM-41 is the most significant factor governing the catalyst selectivity in conversion of $n-C_{7}$. The suitable transport properties (i.e., fast adsorption and desorption) accounts for the high selectivity of the composites towards branched compounds. While, too small diffusion coefficients in zeolite result in longer residence time of reaction intermediates and thus it enhances the probability for subsequent reactions to run. Hence, the preparing of AlSBA-15-BEA support gives the catalyst with the sufficiently diffusion coefficients, where the residence time of carbenium ions is short, what limits the cracking reaction. We believe that the catalytic performance of $\mathrm{Pt} / \mathrm{SBA}-\mathrm{BEA}$ catalytic system results from the occurrence of synergistic effect between the two phases of the composite, i.e., between AlSBA-15 and BEA. The iso-alkanes are formed on acid sites located on BEA zeolite, whereas the AlSBA-15 mesopores allow optimal sorption energetics of the primarily formed isomerization products, preventing their readsorption and further reaction. Another issue that should be taken into account is the presence of secondary mesopores within the zeolite phase in AISBA-15-zeolite composite. As was presented earlier in our work [75] the method of preparation of AlSBA-zeolite supports developed by us has the advantage of creating mesopores not only in the AISBA-15 phase but also in the zeolite phase. It appears that the formation of some kind micropore-mesopore continuity in Pt/SBA-BEA composite may explain their high hydroisomerization efficiency. The secondary mesopores facilitate the accessibility of reactants to the active sites in zeolite, leading to improved catalytic activity in the hydroisomerization. Simultaneously, the shortened residence time of the intermediates in the mesopores diminishes consecutive reactions, such as cracking, enhancing selectivity to isomers. The works of [76-78] have shown that the creation of mesopores in $\mathrm{Pt} / \mathrm{ZSM}-5, \mathrm{Pt} /$ mordenite, and $\mathrm{Pt} / \beta$ catalysts improved their activity in 
$n$-alkane hydroisomerization due to the lifted intracrystalline diffusion limitations in the zeolite pore system.

Summarizing, the Pt/SBA-BEA catalyst displays of: (i) the moderate acidity function as a result of combining low acidic AISBA-15 and strong acidic BEA zeolite, what enhances isomerization and decreases the cracking reactions, (ii) the sufficient metallic function, what facilities the hydrogenation of olefinic intermediates, (iii) micropore-mesopore continuity (the presence of mesopores within AISBA-15 and BEA zeolite) which is responsible for the suitable transport properties and supplies the optimal sorption energies of the reactants. Therefore it may be concluded that the enhanced activity of Pt/SBA-BEA catalytic system is not affecting the hydroisomerization selectivity if the required metal/acidity balance is retained and the diffusion limitations are eliminated.

It should be also noted the differences in activity of the catalysts examined in respect to the $n-C_{7}$ dehydrocyclization. We are aware that aromatization of $n-C_{7}$ is not an objective of the present work, nevertheless we think that these results are noteworthy and apart from discussing hydroisomerization, they deserve a detailed discussion. Therefore, we took also attempts to rationalize the differences in the dehydrocyclization reaction (please see Section 1.5 and Figure S7 in Supplementary Materials).

\subsection{Effect of Active Phase Composition in Pt, Pd, and Pt-Pd Catalysts Supported on AISBA-15-BEA}

Roldán et al. [79] have studied a series of mono- and bimetallic (Pt and/or Pd) catalysts supported on $\beta$ zeolite for hydroisomerization of light $n$-alkanes and they have found that the bimetallic catalyst is significantly more active than the monometallic ones. Also, the work of Bauer et al. [80] has shown that the bimetallic Pt-Pd/ $\beta$ catalysts with overall metal content of $0.8 \mathrm{wt} \%$ displayed high efficiency for $n$-hexadecane hydroisomerization. Bimetallic Pt-Pd catalysts are described to exhibit a higher metal dispersion, thus achieving a high catalytic activity at a lower amount of noble metals than commonly required. In addition, it has been reported that the addition of a second noble metal, especially $\mathrm{Pd}$, in close interaction with Pt significantly improves resistance to poisoning by sulphur and nitrogen compounds present in the processed cuts [81,82]. On the basis of these results, we have studied the effect of hydrogenation components ( $\mathrm{Pt}, \mathrm{Pd}$, or mixtures thereof) supported over the most promising AlSBA-15-BEA support on the hydroisomerization of $n$-heptane. We have expected that Pt and Pd particles can work cooperatively in AlSBA-15BEA supported catalysts, leading to synergistic enhancement in reactivity and selectivity.

From Figure 5 and Table 3, it is seen that the Pd catalyst is the least active catalyst, with an overall conversion of about $30 \%$ lower than that of the catalyst containing Pt or $\mathrm{Pt}-\mathrm{Pd}$ as the hydrogenation components. The Pd/SBA-BEA catalyst is also significantly less effective for isomerization than the Pt having counterpart. This finding is substantiated by the catalyst acidity measurements (Table 1 ) and CO chemisorption results (Table 2) which have proved the higher concentration of acid sites and higher metal dispersion over the Pt/SBA-BEA than over the Pd/SBA-BEA sample. The noticeable difference in the conversion and isomerization efficiency of Pd catalyst is also attributed to the lower hydro-/dehydrogenation function of $\mathrm{Pd}$ in comparison with $\mathrm{Pt}[83,84]$. As a consequence, a smaller amount of intermediate alkenes is formed and consequently lower conversion of $n-\mathrm{C}_{7}$ is achieved.

Activity results (Figure 5) have as well demonstrated that the conversion of $n-C_{7}$ over the $\mathrm{Pt} / \mathrm{SBA}-\mathrm{BEA}$ and $\mathrm{Pt}-\mathrm{Pd} / \mathrm{SBA}-\mathrm{BEA}$ catalysts is comparable at low $\mathrm{T}_{\mathrm{R}}\left(\right.$ at $230^{\circ} \mathrm{C}$ ). At higher temperatures $\left(250-330{ }^{\circ} \mathrm{C}\right)$ the activity of Pt-Pd/SBA-BEA is found even by $5 \%$ lower than Pt/SBA-BEA. In spite of the fact that the doping of Pt-Pd/SBA-BEA catalyst with $P d$ does not bring an increase in $n-C_{7}$ conversion, the distribution of products varies substantially with the Pt-Pd catalyst. As can be inferred from Table 3, the promoting effect of Pd in Pt-Pd/SBA-BEA catalyst is evident, and it brings a growth in hydroisomerization efficiency (by about 10\%) compared to Pt/SBA-BEA one. The Pt-Pd/SBA-BEA catalyst provides the yield $68 \mathrm{wt} \%$ of iso- $C_{7}$ derivatives at a conversion of about $78 \%$. Besides, the $\mathrm{Pt}-\mathrm{Pd} / \mathrm{SBA}-\mathrm{BEA}$ catalyst provides the highest yield of iso- $\mathrm{C}_{7}$ with the highest contribution 
of $\mathrm{MuBC}_{7}$ alkanes. At the same time the Pt-Pd/SBA-BEA gives lower by approx. $10 \%$ yield of $\mathrm{C}_{3}+\mathrm{C}_{4}$ fraction; the cracking products yield over Pt/SBA-BEA catalyst approaches $21 \mathrm{wt} \%$ whereas that over Pt-Pd/SBA-BEA catalyst only $9.9 \mathrm{wt} \%$. Summarizing, the modification of the hydrogenating function by deposition of Pt-Pd active phase on SBABEA increases the hydroisomerization efficiency and brings a small loss of carbon in the cracking products.
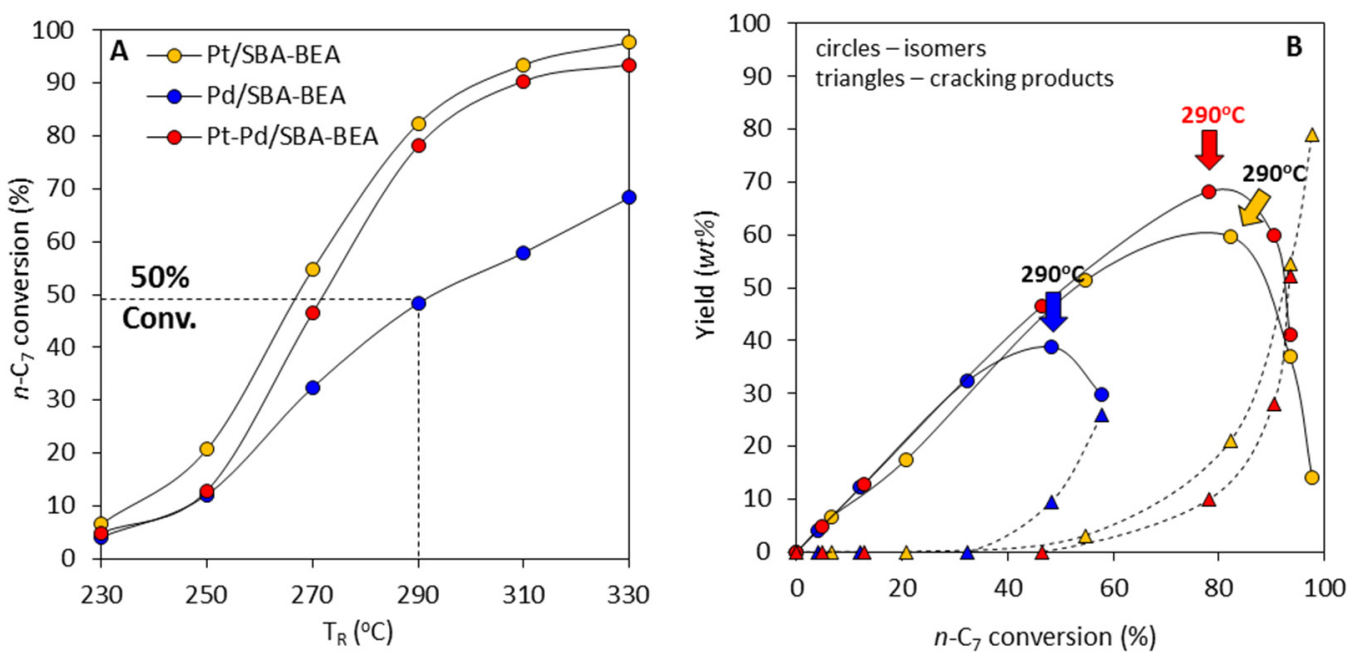

Figure 5. Catalytic performance of the catalysts supported over SBA-BEA: (A) $n-C_{7}$ conversion profiles against $T_{R}$ for $\mathrm{Pt} / \mathrm{SBA}-\mathrm{BEA}, \mathrm{Pd} / \mathrm{SBA}-\mathrm{BEA}$, and Pt-Pd/SBA-BEA and (B) yield of isomers and cracking products against $n-\mathrm{C}_{7}$ conversion for the corresponding catalysts.

In general terms, the increase in the hydroisomerization activity of bimetallic Pt-Pd catalysts is explained by a higher noble metal dispersion caused by a promoting effect of more easily reducible palladium oxides $[80,85]$. The improved Pt-Pd dispersion provides a better proximity and balance of the acidic and metallic species. Interestingly, our findings differ from the results reported by Bauer [80] or Blomsma [85]. In spite of the fact that the Pt$\mathrm{Pd} / \mathrm{SBA}-\mathrm{BEA}$ catalyst displays worse metal dispersion, one can notice that at the same time it provides a higher hydroisomerization efficiency compared to Pt/SBA-BEA. These results are consistent with those presented by Lee et al. [62] who have also observed the enhanced $\mathrm{n}-\mathrm{C}_{7}$ hydroisomerization activity of $\mathrm{Pt}-\mathrm{Pd} / \beta$ catalyst even it has displayed deteriorated dispersion. The authors have claimed that the metal-metal interaction in Pt-Pd $/ \beta$ catalyst accounts for its catalytic performance. Navarro et al. [86] have reported a strong Pt-Pd interaction in $\mathrm{Pt}-\mathrm{Pd} / \mathrm{SiO}_{2} \mathrm{Al}_{2} \mathrm{O}_{3}$ catalyst prepared by using the same precursors as our work $\left(\mathrm{H}_{2} \mathrm{PtCl}_{6}\right.$ and $\left.\mathrm{Pd}\left(\mathrm{NO}_{3}\right)_{2}\right)$. Roldán et al. [87], who prepared the catalysts in the same way as in our investigation (i.e., by coimpregnation), observed the formation of bimetallic Pt-Pd species in Pt-Pd/ $\beta$ catalysts. According to his conclusion the number of hetero-metallic (Pt-Pd) bonds in the coimpregnated catalysts is high enough to provide the enhancement of catalytic properties in relation to the mono-metallic samples. It seems that, the phenomenon of cooperation between $\mathrm{Pt}$ and $\mathrm{Pd}$ accounts for the improved catalytic performance of the composite catalyst compared to the performance of the Pt and Pd catalysts tested separately. However, this idea does not rule out additional possible effects coming from the SBA-BEA support acidity and porous structure. The presence of micro-mesoporous SBA-BEA material as a support is beneficial to Pt-Pd species since its supplies required acidity and the appropriate transport properties. 


\subsection{Research Octane Number}

In order to estimate the antiknocking properties of the liquid isomerizate the Research Octane Number (RON) was calculated using a simple non-linear method described elsewhere $[10,88,89]$ :

$$
R O N=\sum_{i=1}^{k} y_{i} R O N_{i}
$$

where the $R O N_{i}$ index stands for the pure-component octane number for each molecule (that is labelled as $i$, see Section 1.8 and Table $S 4$ in Supplementary Materials) and $y_{i}$ stands for the volume fraction of molecule.

In this equation, $\mathrm{RON}$ is the measured octane number only for branched $C_{7}$ products and does not include lighter than $C_{7}$ products or other side products such as aromatics. We decided to not take into account the RON of light products and aromatics in calculating the final RON for two reasons. To keep sustaining the economy, the refining unit producing liquid fuels requires a minimal production of gases and a maximal yield of liquid products. In our work propane and butanes are the only products lighter than the feed. In spite of being valuable compounds in a view of the RON improvement (they display RON above $100)$, the growth of their yield is not an issue in this calculating RON because it would reduce the liquid $\mathrm{C}_{5+}$ yield. Besides, the light hydrocarbons that would be dissolved in gasoline will increase its volatility and as a consequence the Reid vapour pressure limit would be exceed. Also, the aromatic compounds positively influence the RON of gasoline. However, in our work only the Pt/AlSBA-15 gives the significant quantity of aromatics. Besides, since the regulations aim to limit aromatic components in gasoline, the isomers are more desirable components.

The RON of the branched products obtained over all hierarchical catalysts as a function of $n-C_{7}$ conversion is presented in Figure 6. It is clear that the Pt/AISBA-15-zeolite catalysts ensure higher values of RON than Pt/AlSBA-15 one (Figure 6A). Among the composite Pt catalysts, the $\mathrm{Pt} / \mathrm{SBA}-\mathrm{BEA}$ yields the greatest $\mathrm{RON}$ gain of 64 points and 71 at the maximal isomers yield (at $290{ }^{\circ} \mathrm{C}$ ) and the highest $\mathrm{n}-\mathrm{C}_{7}$ conversion (at $330{ }^{\circ} \mathrm{C}$ ), respectively. In general, the values of $\mathrm{RON}$ increases with the increase of conversion due to the higher contribution of $\mathrm{MuBC}_{7}$ within the reaction products. However, it should be remembered that at high conversions the large quantity of products constitutes propane and butanes.

In the case of the catalysts with modified metallic phase the Pt-Pd/SBA-BEA compared to $\mathrm{Pt}$ and $\mathrm{Pd}$ provides the highest RON amounting to 74 (Figure 6B). This result confirms the described above consideration demonstrating the great hydroisomerization efficiency of bimetallic catalyst supported over SBA-BEA.
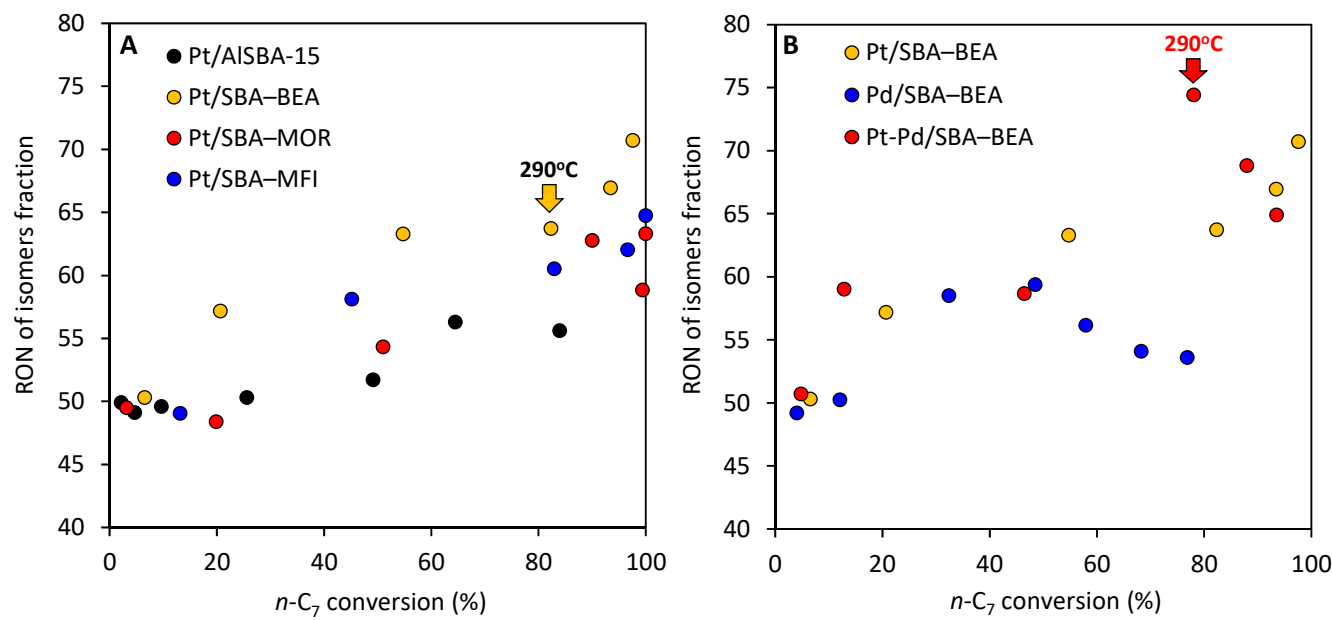

Figure 6. RON number as a function of $n-C_{7}$ conversion: (A) the effect of zeolite type and (B) the effect of metallic phase composition. 


\section{Materials and Methods}

\subsection{Materials}

Materials used for the preparation of the supports and catalysts: tetraethylorthosilicate (TEOS, $\mathrm{Si}\left(\mathrm{OC}_{2} \mathrm{H}_{5}\right)_{4}, 99 \%$, Sigma-Aldrich, St. Louis, MO, USA), aluminium isopropoxide $\left(\left[\left(\mathrm{CH}_{3}\right)_{2} \mathrm{CHO}\right]_{3} \mathrm{Al}\right.$, Aldrich), Pluronic ${ }^{\circledR}$ P-123 (Sigma-Aldrich, average $\mathrm{M}_{\mathrm{n}} \sim 5800$ ), hydrochloric acid ( $\mathrm{HCl}$, Avantor, Radnor, PA, USA), 3\% nitric acid(V) $\left(\mathrm{HNO}_{3}\right.$, Avantor S.A.), aluminium oxyhydroxide ( $\mathrm{AlO}(\mathrm{OH})$, Pural 400, Sasol $\mathrm{GmbH})$, hexachloroplatinic(IV) acid $\left(\mathrm{H}_{2} \mathrm{PtCl}_{6}\right.$, Avantor S.A.), palladium(II) nitrate $\left(\mathrm{Pd}\left(\mathrm{NO}_{3}\right) 2 \times 2 \mathrm{H}_{2} \mathrm{O}\right.$, Sigma-Aldrich), $n$-heptane (Avantor S.A.). A commercial zeolites of $\beta(\mathrm{CP} 811 \mathrm{E}, \mathrm{Si} / \mathrm{Al}=75)$, mordenite $(\mathrm{CBV} 90 \mathrm{~A}, \mathrm{Si} / \mathrm{Al}=45)$ and $\mathrm{ZSM}-5(\mathrm{CBV} 8014, \mathrm{Si} / \mathrm{Al}=80)$ were provided by Zeolyst (Kansas City, KS, USA). Silicon carbide (SiC, Honeywell-Fluka, Charlotte, NC, USA) was used as an inert material for the catalyst dilution. All other chemicals were of analytical grade and used without any further purification. All aqueous solutions were freshly prepared in deionized water.

\subsection{Supports and Catalysts Preparation}

AlSBA-15 material with $\mathrm{Si} / \mathrm{Al}$ ratio of 7 was synthesized following the procedure described in by Vinu et al. [90]. Pluronic P123 (4.0 g) was dissolved in $30 \mathrm{~mL}$ of distilled water and stirred for $2 \mathrm{~h}$. Subsequently, $70 \mathrm{~mL}$ of $0.28 \mathrm{M}$ hydrochloric acid was added and mixed until the solution became homogenous (about $2 \mathrm{~h}$ ). Then, $8.5 \mathrm{~g}$ TEOS was added along with $1.2 \mathrm{~g}$ of aluminum isopropoxide and the obtained mixture was then stirred for $24 \mathrm{~h}$ at $40{ }^{\circ} \mathrm{C}$. Next, the synthesis gel (with molar composition of 1TEOS:0.12 $\mathrm{Al}_{2} \mathrm{O}_{3}: 0.016 \mathrm{P} 123: 0.50 \mathrm{HCl}$ : $136 \mathrm{H}_{2} \mathrm{O}$ ) was transferred to PTFE bottle and heated at $120^{\circ} \mathrm{C}$ for $24 \mathrm{~h}$ under static conditions. The resulting solid material was filtered and washed with distilled water a few times and then dried for $12 \mathrm{~h}$ at $100{ }^{\circ} \mathrm{C}$. The as-synthesized AlSBA-15 sample was calcined at $550{ }^{\circ} \mathrm{C}$ for $6-8 \mathrm{~h}$ to remove the structure directing agent.

AISBA-15-zeolite composites were synthesized by following the facile procedure illustrated in Figure 7. First, the initial stage of AlSBA-15 phase synthesis was realized and after $24 \mathrm{~h}$ gel stirring at $40{ }^{\circ} \mathrm{C}$ the synthesis was stopped (Step A). Then, $20 \mathrm{wt} \%$ zeolite ( $\beta$, ZSM-5 or mordenite) was added and the resulting suspension was stirred for a few minutes (Step B). Finally, the mixture was aged hydrothermally at $120^{\circ} \mathrm{C}$ for $24 \mathrm{~h}$ in PTFE bottle (Step C). Solid products were filtered and washed using deionized water until neutral $\mathrm{pH}$. The as-synthesized micro-mesoporous materials were dried at $110{ }^{\circ} \mathrm{C}$ and then calcined at $550^{\circ} \mathrm{C}$ for $6-8 \mathrm{~h}$. The obtained AlSBA-15-zeolite composites (where zeolite is: $\beta, \mathrm{ZSM}-5$ or mordenite) were denoted as SBA-BEA, SBA-MFI and SBA-MOR, respectively.

$\mathrm{Pt}, \mathrm{Pd}$, and Pt-Pd catalysts were prepared via incipient wetness impregnation. The powders of zeolites, AlSBA-15 material or AlSBA-15-zeolite were mixed with $20 \mathrm{wt} \%$ of aluminium oxyhydroxide (after calcination $\gamma-\mathrm{Al}_{2} \mathrm{O}_{3}$ ) which was used as a binder. The resulting mixtures were peptised with $3 \% \mathrm{HNO}_{3}$ and then shaped into cylindrical pieces. The resulting pellets were subjected to drying for $12 \mathrm{~h}$ at $110{ }^{\circ} \mathrm{C}$ and then calcination at $450{ }^{\circ} \mathrm{C}$ for $24 \mathrm{~h}$. Pt and Pd catalysts with the nominal concentration of $0.5 \mathrm{wt} \%$ were prepared via impregnation of already formed and calcined pieces $(0.40-0.63 \mathrm{~mm})$ using $\mathrm{H}_{2} \mathrm{PtCl}_{6}$ or $\mathrm{Pd}\left(\mathrm{NO}_{3}\right) 2 \times 2 \mathrm{H}_{2} \mathrm{O}$, respectively. After impregnation, the samples were dried at RT $(24 \mathrm{~h}), 100{ }^{\circ} \mathrm{C}(12 \mathrm{~h})$, and then calcined at $450{ }^{\circ} \mathrm{C}(3 \mathrm{~h})$. Pt-Pd/SBA-BEA catalyst was prepared by one-step impregnation with a solution of $\mathrm{H}_{2} \mathrm{PtCl}_{6}$ and $\mathrm{Pd}\left(\mathrm{NO}_{3}\right)_{2} \times 2 \mathrm{H}_{2} \mathrm{O}$. The Pt-Pd catalyst was loaded with $0.25 \mathrm{wt} \%$ of $\mathrm{Pt}$ and $0.25 \mathrm{wt} \% \mathrm{Pd}$ to maintaining an overall metal content of $0.5 \mathrm{wt} \%$. The incipient wetness impregnation of pelleted supports was chosen as the most common metal incorporation procedure in industrial catalyst preparation and with the awareness that the part of the metal will be deposited on the binder. The thermal treatment of the bimetallic catalyst was carried out at the same conditions as for the monometallic one. 


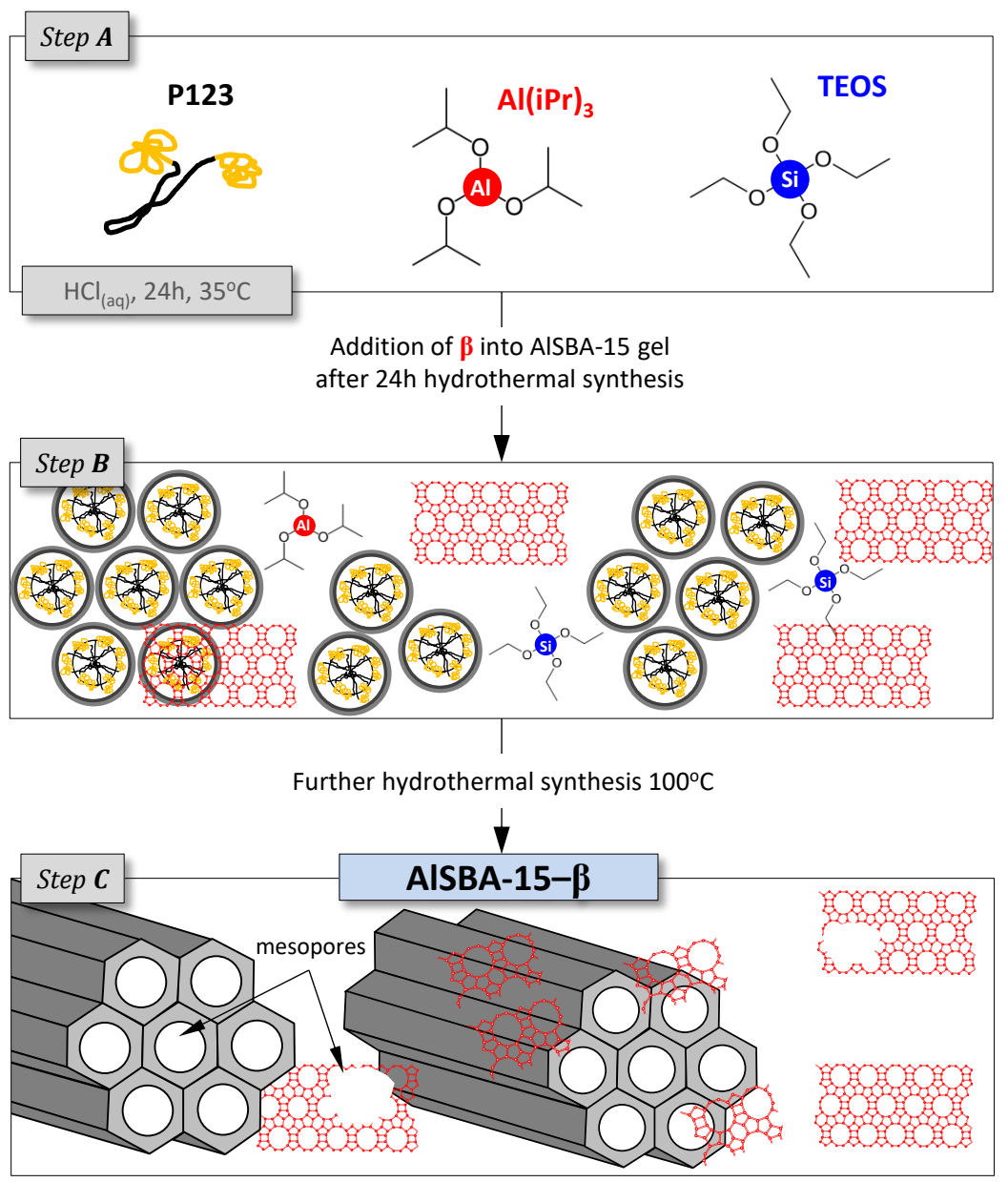

Figure 7. Preparation scheme of the micro-mesoporous composite material AlSBA-15 + zeolite (in the diagram AlSBA-15- $\beta$ is presented as an example); (A) initial synthesis of AlSBA-15, (B) addition of zeolite into the AlSBA-15 gel, and (C) hydrothermal treatment of resulting mixture.

\subsection{Catalyst Characterisation}

The textural properties of the materials were measured by the nitrogen adsorption at $-196{ }^{\circ} \mathrm{C}$, using an Autosorb-1C Quantachrome analyser (Quantachrome Instruments, Boynton Beach, FL, USA). Prior to the adsorption measurements, the samples were degassed in vacuum at $150{ }^{\circ} \mathrm{C}$ for $24 \mathrm{~h}$ (analysis time $13 \mathrm{~h}$ ). Total surface area of the samples was determined using BET model. Distribution of pore sizes was calculated according to Barrett-Joyner-Halenda method (BJH).

Powder XRD data of the samples were recorded in X'Pert Pro equipment (PANalytical, Almelo, Netherlands) with $\mathrm{CuK} \alpha$ radiation $(0.154 \mathrm{~nm}, \mathrm{~A}, 40 \mathrm{kV}, 40 \mathrm{~mA})$. Scanning was carried out with $0.026^{\circ}$ step and in range from $0.5^{\circ}$ to $5^{\circ}$ and from $10^{\circ}$ to $80^{\circ}(2 \theta)$ for mesoporous AlSBA-15 and zeolites, respectively.

Acidity of the samples was determined using pyridine adsorption (Py-IR). IR spectra were registered using a Vector 22 spectrophotometer (Bruker, Billerica, MA, USA). Tablets made out of catalyst samples were put inside FTIR quartz chamber and degassed using vacuum at $400{ }^{\circ} \mathrm{C}$ for $1 \mathrm{~h}$. After that, the samples were saturated with pyridine at $150{ }^{\circ} \mathrm{C}$ and desorbed at $150,200,250,300$ and $350^{\circ} \mathrm{C}$ in vacuum for $30 \mathrm{~min}$. IR spectra were registered in 1400-1700 $\mathrm{cm}^{-1}$ range. Concentration of Brønsted and Lewis acidic sites was calculated based on 1545 and $1455 \mathrm{~cm}^{-1}$ frequencies. The strength of the acidic sites was calculated as $\mathrm{A}_{350} / \mathrm{A}_{150}$, where $\mathrm{A}_{150}$ denotes the absorbance after chemisorption of $P y$ at $150{ }^{\circ} \mathrm{C}$, and $\mathrm{A}_{350}$ is the absorbance after desorption of $P y$ at $350^{\circ} \mathrm{C}$.

$\mathrm{CO}$ pulse chemisorption has been used to estimate the metal phase dispersion. The experiments were performed in U-shaped quartz fixed-bed flow reactor coupled with a 
mass spectrometer (QMG 220 PRISMA PLUS, PFEIFFER, Aßlar, Germany). The sample (25 mg) was first reduced in $5 \mathrm{vol} \% \mathrm{H}_{2} /$ Ar flow $\left(30 \mathrm{~mL} / \mathrm{min}\right.$ ) at $450{ }^{\circ} \mathrm{C}$ for $1 \mathrm{~h}$. After cooling down to room temperature (RT) under He flow the system was equilibrated. Then the pulses of $2 \mathrm{vol} \% \mathrm{CO} /$ Ar mixture (loop volume was $250 \mu \mathrm{L}$ ) was periodically injected until saturation. The average metal particle size, metal dispersion, and metal surface area were calculated based on the procedure described by Fagherazzi et al. [91].

The structure of the samples was investigated with a CM-20 microscope (Philips, Amsterdam, Netherlands) operating at $100 \mathrm{kV}$. Prior to observation, the samples were ultrasonically dispersed in ethanol and transferred to a holey carbon coated copper grid (300 mesh).

\subsection{Catalytic Activity Measurements}

The transformation of $n$-heptane $\left(n-C_{7}\right)$ was carried out in a high-pressure stainless steel tubular flow reactor (i.d. of $8 \mathrm{~mm}$ and catalyst bed approximately $80 \mathrm{~mm}$ long) under $1 \mathrm{~atm}$. The catalyst bed was composed of $3 \mathrm{~cm}^{3}$ of the catalyst grains with $0.4-0.63 \mathrm{~mm}$ particle size, diluted with $1 \mathrm{~cm}^{3}$ of $\mathrm{SiC}(0.25 \mathrm{~mm}$ particle size). Experiments were conducted at $\mathrm{H}_{2}: \mathrm{CH}=10: 1 \mathrm{~mol} / \mathrm{mol}, \mathrm{WHSV}=1 \mathrm{~h}^{-1}$, and the temperature $250-350{ }^{\circ} \mathrm{C}$. Before the test, the catalyst was reduced under a hydrogen flow at $450{ }^{\circ} \mathrm{C}$ for $3 \mathrm{~h}$. Reaction products were analysed by the GC method (FID detector), using the Elite Petro capillary column $(100 \mathrm{~m} \times 0.25 \mathrm{~mm} \times 0.5 \mu \mathrm{m})$. The reaction products have been grouped as follows:

(1) iso- $_{7}$ (total hydroisomerization products), including $\mathrm{MoBC}_{7}$ (monobranched isomers) and $\mathrm{MuBC}_{7}$ (multibranched isomers),

(2) $\mathrm{C}_{3}+\mathrm{C}_{4}$ (hydrocracking products),

(3) Aro \& Cyc, i.e., aromatics (mostly toluene) and cycloalkanes (mostly methylcyclohexane).

All the tested catalysts exhibited no hydrogenolysis activity, i.e., none yield of methane and ethane was observed. Additionally high molecular compounds were not detected. Results from a reproduced experiment showed that the conversion and product efficiency had an error of $\pm 2.5 \%$.

\section{Conclusions}

In this work we reported the hydroisomerization of $n$-heptane $\left(n-C_{7}\right)$ towards the high octane isomers with by using bifunctional $\mathrm{Pt}(\mathrm{Pd})$ catalysts supported over AlSBA-15zeolite hierarchical composites (where zeolite is $\beta$, mordenite or ZSM-5, denoted as BEA, MOR and MFI, respectively). The AISBA-15-zeolite materials were effectively prepared through novel one-step strategy. Research was undertaken to examine: (i) the influence of zeolite incorporated into AlSBA-15-zeolite biporous supports on the activity of $\mathrm{Pt}(0.5 \mathrm{wt} \%)$ catalysts and (ii) the influence of the metallic phase composition (i.e., Pt, Pd or Pt-Pd, with overall metal content of $0.5 \mathrm{wt} \%$ ) on the catalytic performance of the catalysts supported over the most favourable AlSBA-15-BEA support. All the catalysts were prepared by extrusion of the mixture of powdered AlSBA-15-zeolite material with a binder (i.e., $20 \mathrm{wt} \%$ of boehmite) followed by impregnation. The results in this investigation can be summarized in the following conclusions:

(1) The results clearly show that type of the zeolite (BEA, MOR and MFI) that was introduced into AlSBA-15-zeolite hierarchical supports significantly affects the activity of $\mathrm{Pt}$ catalysts in $n-\mathrm{C}_{7}$ hydroisomerization. The Pt/AlSBA-15-BEA catalyst displays the most promising catalytic properties for the isomerization of $n-C_{7}$, relative to Pt/AlSBA-15 and Pt/zeolite and to the two other catalysts (Pt/AlSBA-15-MOR and $\mathrm{Pt} / \mathrm{AlSBA}-15-\mathrm{MFI})$. The maximal yield of heptane isomers over Pt/AlSBA-15-BEA amounting to ca. $60 \%$ is reached at $82 \%$ of the total $n-C_{7}$ conversion (at $290{ }^{\circ} \mathrm{C}$ ). This catalyst allows to improve research octane number from 0 to 64 . The enhanced performance over $\mathrm{Pt} / \mathrm{AlSBA}-15-\mathrm{BEA}$ catalyst is attributed to not only the well $\mathrm{Pt}$ dispersion and moderate acidity but also to the improved textural properties. The method of preparation of biporous supports developed by us provides the formation 
of some kind micropore-mesopore continuity in AlSBA-15-zeolite which facilitates the suitable transport properties (i.e., fast adsorption and desorption). The presence of mesopores decreases or eliminates diffusion restrictions. It shortens the residence time of the intermediates in catalyst pores and results in diminution of consecutive reactions, such as cracking, and consequently in enhancing isomerization efficiency.

(2) The research onto the modification of the hydrogenating function $(\mathrm{Pt}, \mathrm{Pd}, \mathrm{Pt}-\mathrm{Pd})$ has shown that the most remarkable case is that of the Pt-Pd synergy. Combining $\mathrm{Pt}$ and $\mathrm{Pd}$ led to a notable synergetic effect, which exceed those of the additive contribution of $\mathrm{Pt}$ and $\mathrm{Pd}$ in the metallic phase. The hydroisomerization of $n$ - $\mathrm{C}_{7}$ over $\mathrm{Pt}-\mathrm{Pd} / \mathrm{AlSBA}-15-\mathrm{BEA}$ catalyst provides the yield of isomers amounting to $68 \mathrm{wt} \%$ without extensive cracking at conversion of up to $78 \%$ (at $290{ }^{\circ} \mathrm{C}$ ). The Pt-Pd/AlSBA15-BEA catalyst allows to improve research octane number from 0 to 74 . The high isomerization activity of Pt-Pd/AlSBA-15-BEA catalyst can be considered to come from the micro-mesoporous AISBA-15-BEA support which supplies a required acidity characterisation and the appropriate transport properties. But first of all the observed synergy in Pt-Pd/ AlSBA-15-BEA catalyst could most likely be attributed to the interaction between $\mathrm{Pt}$ and $\mathrm{Pd}$ particles.

Supplementary Materials: The following are available online at https:/ /www.mdpi.com/2073-434 4/11/3/377/s1, Figure S1: Characterization of the Pt catalysts; (A) $\mathrm{N}_{2}$ adsorption (full symbols) desorption isotherms (open symbols) and pore size distribution and (B) XRD patterns and TEM images of: (a) AlSBA-15 and (b) Pt/AlSBA-15 samples. Figure S2: $\mathrm{N}_{2}$ adsorption-desorption isotherms and pore size distribution (as an inclusion) for: (a) Pt/SBA-BEA, (b) Pd/SBA-BEA and (c) Pt-Pd/SBA-BEA catalysts. Figure S3: Low-angle XRD patterns for: (a) Pt/SBA-BEA, (b) Pd/SBABEA and (c) Pt-Pd/SBA-BEA catalysts. Figure S4: XRD patterns collected for: (a) beta zeolite, (b) $\mathrm{Pt} / \mathrm{SBA}-\mathrm{BEA},(\mathrm{c}) \mathrm{Pd} / \mathrm{SBA}-\mathrm{BEA}$ and (d) Pt-Pd/SBA-BEA samples. Figure S5: Catalytic performance of the Pt/zeolite catalysts: (A) $n-C_{7}$ conversion profiles against $T_{R}$ and (B) yield of isomers and cracking products against $n-C_{7}$ conversion for the corresponding catalysts. Figure S6: Arrhenius plots $n-C_{7}$ hydroconversion over Pt/AlSBA-15-zeolite catalysts. Figure S7: Reaction pathway for the dehydro-/cyclization of $n$-alkanes over monofunctional and bifunctional catalysts. Table S1: Textural properties of the supports and the catalysts. Table S2: Performance of the catalysts in the hydroconversion of $n-C_{7}$. Table S3: Physicochemical characteristics of the catalysts: ratio of metal to Brønsted acid sites $\left(n_{M_{-} A} / n_{P y H^{+}}\right)$and Lewis to Brønsted acid sites $\left(n_{P y L} / n_{P y H^{+}}\right)$. Table S4: Octane number data for hydrocarbons present in isomerization product of $n-C_{7}$.

Author Contributions: Conceptualization, K.J., M.F. and A.M.; methodology, K.J., M.F. and A.M.; software, K.J.; validation, K.J., M.F., R.Ł. and J.T.; formal analysis, K.J., M.F. and A.M., investigation, M.F. and R.Ł.; resources; K.J.; data curation, M.F.; writing-original draft preparation, K.J.; writingreview and editing, K.J.; visualization, K.J.; supervision, K.J.; project administration, J.T.; funding acquisition, J.T. All authors have read and agreed to the published version of the manuscript.

Funding: The work was supported by a statutory activity subsidy from the Ministry of Science and Higher Education, Republic of Poland for the Faculty of Chemistry of Wrocław University of Science and Technology (8201003902).

Data Availability Statement: The authors confirm that the data supporting the findings of this study are available within the article and its supplementary materials.

Acknowledgments: We thank Gill, B. (Jagiellonian University in Kraków) for Py-IR measurements and Śliwa, M. (Jerzy Haber Institute of Catalysis and Surface Chemistry, Polish Academy of Sciences) for $\mathrm{CO}$ chemisorption analyses. Sasol is acknowledged for providing the alumina binder.

Conflicts of Interest: The authors declare that they have no known competing financial interests or personal relationships that could have appeared to influence the work reported in this paper. 


\section{References}

1. Mascal, M.; Dutta, S. Synthesis of highly-branched alkanes for renewable gasoline. Fuel Process. Technol. 2020, 197, 106192. [CrossRef]

2. Kiatkittipong, W.; Wongsakulphasatch, S.; Tintan, N.; Laosiripojana, N.; Praserthdam, P.; Assabumrungrat, S. Gasoline upgrading by self-etherification with ethanol on modified beta-zeolite. Fuel Process. Technol. 2011, 92, 1999-2004. [CrossRef]

3. Said, M.M.; Ahmed, T.S.; Moustafa, T.M. Predictive Modeling and Optimization for an Industrial Penex Isomerization Unit: A Case Study. Energy Fuels 2014, 28, 7726-7741. [CrossRef]

4. Bellussi, G.; Pollesel, P. Industrial applications of zeolite catalysis: Production and uses of light olefins. In Studies in Surface Science and Catalysis; Elsevier: Amsterdam, The Netherlands, 2005; Volume 158, pp. 1201-1212. [CrossRef]

5. Kuchar, P.; Bricker, J.; Reno, M.; Haizmann, R. Paraffin isomerization innovations. Fuel Process. Technol. 1993, 35, 183-200. [CrossRef]

6. Kimura, T. Development of $\mathrm{Pt} / \mathrm{SO}_{42}-/ \mathrm{ZrO}_{2}$ catalyst for isomerization of light naphtha. Catal. Today 2003, 81, 57-63. [CrossRef]

7. Tanabe, K. Industrial application of solid acid-base catalysts. Appl. Catal. A Gen. 1999, 181, 399-434. [CrossRef]

8. Ramírez-Corredores, M.M.; Reomero, T.; González, M. Dehydroisomerization of N-butane on $\mathrm{Pt}=\mathrm{Zn} / \mathrm{H}-\mathrm{Mordenite}$. Pharmacogenetics 2000, 130 C, 2507-2512. [CrossRef]

9. Hidalgo, J.; Zbuzek, M.; Černý, R.; Jǐša, P.; Herrador, J.M.H. Current uses and trends in catalytic isomerization, alkylation and etherification processes to improve gasoline quality. Open Chem. 2014, 12, 1-13. [CrossRef]

10. Busto, M.; Vera, C.; Grau, J. Optimal process conditions for the isomerization-cracking of long-chain n-paraffins to high octane isomerizate gasoline over $\mathrm{Pt} / \mathrm{SO}_{42}-\mathrm{ZrO}_{2}$ catalysts. Fuel Process. Technol. 2011, 92, 1675-1684. [CrossRef]

11. Pope, T.D.; Kriz, J.F.; Stanciulescu, M.; Monnier, J. A study of catalyst formulations for isomerization of C7 hydrocarbons. Appl. Catal. A Gen. 2002, 233, 45-62. [CrossRef]

12. Meyer, C.; Hager, V.; Schwieger, W.; Wasserscheid, P. Enhanced activity and selectivity in n-octane isomerization using a bifunctional SCILL catalyst. J. Catal. 2012, 292, 157-165. [CrossRef]

13. Meneses-Ruiz, E.; Laredo, G.C.; Castillo, J.; Marroquin, J.O. Comparison of different molecular sieves for the liquid phase separation of linear and branched alkanes. Fuel Process. Technol. 2014, 124, 258-266. [CrossRef]

14. Silke, E.J.; Curran, H.J.; Simmie, J.M. The influence of fuel structure on combustion as demonstrated by the isomers of heptane: A rapid compression machine study. Proc. Combust. Inst. 2005, 30, 2639-2647. [CrossRef]

15. Wang, W.; Liu, C.-J.; Wu, W. Bifunctional catalysts for the hydroisomerization of n-alkanes: The effects of metal-acid balance and textural structure. Catal. Sci. Technol. 2019, 9, 4162-4187. [CrossRef]

16. Luo, J.; Arroyo-Ramírez, L.; Wei, J.; Yun, H.; Murray, C.B.; Gorte, R.J. Comparison of HMF hydrodeoxygenation over different metal catalysts in a continuous flow reactor. Appl. Catal. A Gen. 2015, 508, 86-93. [CrossRef]

17. Bond, J.Q.; Upadhye, A.A.; Olcay, H.; Tompsett, G.A.; Jae, J.; Xing, R.; Alonso, D.M.; Wang, D.; Zhang, T.; Kumar, R.; et al. Production of renewable jet fuel range alkanes and commodity chemicals from integrated catalytic processing of biomass. Energy Environ. Sci. 2014, 7, 1500-1523. [CrossRef]

18. Guisnet, M. “Ideal” bifunctional catalysis over Pt-acid zeolites. Catal. Today 2013, 218, 123-134. [CrossRef]

19. Niu, P.; Liu, P.; Xi, H.; Ren, J.; Lin, M.; Wang, Q.; Chen, X.; Jia, L.; Hou, B.; Li, D. Design and synthesis of Pt/ZSM-22 catalysts for selective formation of iso-Dodecane with branched chain at more central positions from n-Dodecane hydroisomerization. Appl. Catal. A Gen. 2018, 562, 310-320. [CrossRef]

20. Yang, Z.; Liu, Y.; Liu, D.; Meng, X.; Liu, C. Hydroisomerization of n-octane over bimetallic Ni-Cu/SAPO-11 catalysts. Appl. Catal. A Gen. 2017, 543, 274-282. [CrossRef]

21. Mishra, G.S.; Kumar, A. Hydroisomerization of saturated hydrocarbons with novel MCM-41 immobilized Re(V) complex catalysts. Appl. Catal. A Gen. 2012, 429-430, 1-8. [CrossRef]

22. Chen, J.; Cai, T.; Jing, X.; Zhu, L.; Zhou, Y.; Xiang, Y.; Xia, D. Surface chemistry and catalytic performance of amorphous NiB/H $\beta$ catalyst for n-hexane isomerization. Appl. Surf. Sci. 2016, 390, 157-166. [CrossRef]

23. Zhao, X.; Liu, W.; Wang, J.; Yang, W.; Zhu, X.; Zhu, K. Interface mediated crystallization of plate-like SAPO-41 crystals to promote catalytic hydroisomerization. Appl. Catal. A Gen. 2020, 602, 117738. [CrossRef]

24. Liua, L.; Zhanga, M.; Wangab, L.; Zhangab, X.; Liab, G. Construction of ordered mesopores outside MTT zeolite for efficient hydroisomerization. Appl. Catal. A Gen. 2020,602, 117664. [CrossRef]

25. Pastvova, J.; Pilar, R.; Moravkova, J.; Kaucký, D.; Rathousky, J.; Sklenak, S.; Sazama, P. Tailoring the structure and acid site accessibility of mordenite zeolite for hydroisomerisation of n-hexane. Appl. Catal. A Gen. 2018, 562, 159-172. [CrossRef]

26. Contreras, J.; Fuentes, G.A.; Navarrete, J.T.L.; Vazquez, A.L.; Zeifert, B.; Salmones, J.; Nuño, L. Structural and catalytic characterization of mechanical mixtures of $\mathrm{Pt} / \mathrm{WO}_{\mathrm{x}}-\mathrm{ZrO}_{2}$ and $\mathrm{Al}_{2} \mathrm{O}_{3}$. J. Alloy. Compd. 2010, 495, 466-470. [CrossRef]

27. Sánchez, P.; Dorado, F.; Ramos, M.J.; Romero, R.; Jiménez, V.; Valverde, J.L.; Marcos, M.J.R. Hydroisomerization of C6-C8 $\mathrm{n}$-alkanes, cyclohexane and benzene over palladium and platinum beta catalysts agglomerated with bentonite. Appl. Catal. A Gen. 2006, 314, 248-255. [CrossRef]

28. Gao, L.; Shi, Z.; Etim, U.J.; Wu, P.; Xing, W.; Zhang, Y.; Bai, P.; Yan, Z. Superior catalytic performance of micro-mesoporous Beta-SBA-15 composite with a high indexed isomerization factor in hydroisomerization of n-heptane. Fuel 2019, 252, 653-665. [CrossRef] 
29. Gao, L.; Shi, Z.; Etim, U.J.; Wu, P.; Han, D.; Xing, W.; Mintova, S.; Bai, P.; Yan, Z. Beta-MCM-41 micro-mesoporous catalysts in the hydroisomerization of n-heptane: Definition of an indexed isomerization factor as a performance descriptor. Microporous Mesoporous Mater. 2019, 277, 17-28. [CrossRef]

30. Lakiss, L.; Gilson, J.-P.; Valtchev, V.; Mintova, S.; Vicente, A.; Vimont, A.; Bedard, R.; Abdo, S.; Bricker, J. Zeolites in a good shape: Catalyst forming by extrusion modifies their performances. Microporous Mesoporous Mater. 2020, 299, 110114. [CrossRef]

31. Izan, S.; Triwahyono, S.; Jalil, A.; Majid, Z.; Fatah, N.; Hamid, M.; Ibrahim, M. Additional Lewis acid sites of protonated fibrous silica@BEA zeolite (HSi@BEA) improving the generation of protonic acid sites in the isomerization of C6 alkane and cycloalkanes. Appl. Catal. A Gen. 2019, 570, 228-237. [CrossRef]

32. Palčić, A.; Valtchev, V. Analysis and control of acid sites in zeolites. Appl. Catal. A Gen. 2020, 606, 117795. [CrossRef]

33. Chen, X.; Liu, J.; Yan, H.; Zhou, X.; Yao, S.; Wang, Y.; Liang, W.; Guo, Z.; Liu, Y.; Feng, X.; et al. Insight into the Effect of Lewis Acid of W/Al-MCM-41 Catalyst on Metathesis of 1-Butene and Ethylene. Appl. Catal. A Gen. 2020, 604, 117772. [CrossRef]

34. Bukhtiyarova, M.; Toktarev, A.; Kazakov, M.; Kodenev, E.; Pereyma, V.Y.; Gabrienko, A.; Echevsky, G. Effect of sulfosalicylic acid treatment on the properties of Beta zeolite and performance of NiW/Beta-based catalysts in hexadecane hydrocracking. Appl. Catal. A Gen. 2020, 598, 117573. [CrossRef]

35. Etim, U.; Bai, P.; Wang, Y.; Subhan, F.; Liu, Y.; Yan, Z. Mechanistic insights into structural and surface variations in Y-type zeolites upon interaction with binders. Appl. Catal. A Gen. 2019, 571, 137-149. [CrossRef]

36. Wang, B.; Yan, X.; Zhang, X.; Zhang, H.; Li, F. Citric acid-modified beta zeolite for polyoxymethylene dimethyl ethers synthesis: The textural and acidic properties regulation. Appl. Catal. B Environ. 2020, 266, 118645. [CrossRef]

37. Velisoju, V.K.; Gutta, N.; Tardio, J.; Bhargava, S.K.; Vankudoth, K.; Chatla, A.; Medak, S.; Akula, V. Hydrodeoxygenation activity of W modified Ni/H-ZSM-5 catalyst for single step conversion of levulinic acid to pentanoic acid: An insight on the reaction mechanism and structure activity relationship. Appl. Catal. A Gen. 2018, 550, 142-150. [CrossRef]

38. Busca, G. Catalytic materials based on silica and alumina: Structural features and generation of surface acidity. Prog. Mater. Sci. 2019, 104, 215-249. [CrossRef]

39. Iliopoulou, E.F.; Heracleous, E.; Delimitis, A.; Lappas, A.A. Producing high quality biofuels: Pt-based hydroisomerization catalysts evaluated using BtL-naphtha surrogates. Appl. Catal. B Environ. 2014, 145, 177-186. [CrossRef]

40. Villegas, J.; Kubička, D.; Karhu, H.; Österholm, H.; Kumar, N.; Salmi, T.; Murzin, D. On the mutual interactions between noble metal crystallites and zeolitic supports and their impacts on catalysis. J. Mol. Catal. A Chem. 2007, 264, 192-201. [CrossRef]

41. Leckel, D. Noble Metal Wax Hydrocracking Catalysts Supported on High-Siliceous Alumina. Ind. Eng. Chem. Res. 2007, 46, 3505-3512. [CrossRef]

42. Kubička, D.; Kumar, N.; Venäläinen, T.; Karhu, H.; Kubičková, I.; Österholm, H.; Murzin, D.Y. Metal-Support Interactions in Zeolite-Supported Noble Metals: Influence of Metal Crystallites on the Support Acidity. J. Phys. Chem. B 2006, 110, $4937-4946$. [CrossRef]

43. Koningsberger, D.; De Graaf, J.; Mojet, B.; Ramaker, D.; Miller, J. The metal-support interaction in Pt/Y zeolite: Evidence for a shift in energy of metal d-valence orbitals by Pt-H shape resonance and atomic XAFS spectroscopy. Appl. Catal. A Gen. 2000, 191, 205-220. [CrossRef]

44. Yu, Y.; Gutiérrez, O.Y.; Haller, G.L.; Colby, R.; Kabius, B.; Van Veen, J.R.; Jentys, A.; Lercher, J.A. Tailoring silica-alumina-supported $\mathrm{Pt}-\mathrm{Pd}$ as poison-tolerant catalyst for aromatics hydrogenation. J. Catal. 2013, 304, 135-148. [CrossRef]

45. Xu, L.; Zhang, Z.; Sachtler, W.M.H. Effect of zeolite protons on Pd particle size and $\mathrm{H}_{2}$ chemisorption. J. Chem. Soc. Faraday Trans. 1992, 88, 2291-2295. [CrossRef]

46. Yao, J.; Yao, Y. Investigation of zeolite supported platinum electrocatalyst for electrochemical oxidation of small organic species. Int. J. Hydrog. Energy 2016, 41, 14747-14757. [CrossRef]

47. Aboul-Gheit, N.A.K. Effect of Hydrohalogenation of Metal/Zeolite Catalysts for Cyclohexene Hydroconversion -Part 3- Pd/HZSM-5 Catalysts. J. Chin. Chem. Soc. 2007, 54, 1211-1222. [CrossRef]

48. Li, Z.; Ji, S.; Liu, Y.; Cao, X.; Tian, S.; Chen, Y.; Niu, Z.; Li, Y. Well-Defined Materials for Heterogeneous Catalysis: From Nanoparticles to Isolated Single-Atom Sites. Chem. Rev. 2020, 120, 623-682. [CrossRef] [PubMed]

49. Treesukol, P.; Srisuk, K.; Limtrakul, J.; Truong, T.N. Nature of the Metal-Support Interaction in Bifunctional Catalytic Pt/H-ZSM-5 Zeolite. J. Phys. Chem. B 2005, 109, 11940-11945. [CrossRef]

50. Lónyi, F.; Kovács, A.; Szegedi, Á.; Valyon, J. Activation of Hydrogen and Hexane over Pt,H-Mordenite Hydroisomerization Catalysts. J. Phys. Chem. C 2009, 113, 10527-10540. [CrossRef]

51. Qi, S.-C.; Wei, X.-Y.; Zong, Z.-M.; Wang, Y.-K. Application of supported metallic catalysts in catalytic hydrogenation of arenes. RSC Adv. 2013, 3, 14219-14232. [CrossRef]

52. Liu, H.; Lei, G.D.; Sachtler, W.M.H. Alkane isomerization over solid acid catalysts Effects of one-dimensional micropores. Appl. Catal. A Gen. 1996, 137, 167-177. [CrossRef]

53. Jaroszewska, K.; Masalska, A.; Grzechowiak, J.; Grams, J. Hydroconversion of 1-methylnaphthalene over Pt/AlSBA-15-Al ${ }_{2} \mathrm{O}_{3}$ composite catalysts. Appl. Catal. A Gen. 2015, 505, 116-130. [CrossRef]

54. Sobczak, I. The role of niobium in MCM-41 supported with Pt and Au-A comparative study of physicochemical and catalytic properties. Catal. Today 2009, 142, 258-266. [CrossRef]

55. Samad, J.E.; Blanchard, J.; Sayag, C.; Louis, C.; Regalbuto, J.R. The controlled synthesis of metal-acid bifunctional catalysts: Selective Pt deposition and nanoparticle synthesis on amorphous aluminosilicates. J. Catal. 2016, 342, 213-225. [CrossRef] 
56. Samad, J.E.; Blanchard, J.; Sayag, C.; Louis, C.; Regalbuto, J.R. The controlled synthesis of metal-acid bifunctional catalysts: The effect of metal:acid ratio and metal-acid proximity in $\mathrm{Pt}$ silica-alumina catalysts for n-heptane isomerization. J. Catal. 2016, 342, 203-212. [CrossRef]

57. Aboul-Fotouh, S.M.; Aboul-Gheit, A. Effect of Hydrohalogenation of PtRe/H-ZSM-5 for Cyclohexene Conversion. Chin. J. Catal. 2012, 33, 697-705. [CrossRef]

58. Karhu, H.; Kalantar, A.; Väyrynen, I.; Salmi, T.; Murzin, D. XPS analysis of chlorine residues in supported Pt and Pd catalysts with low metal loading. Appl. Catal. A Gen. 2003, 247, 283-294. [CrossRef]

59. Jongpatiwut, S.; Rattanapuchapong, N.; Rirksomboon, T.; Osuwan, S.; Resasco, D.E. Enhanced Sulfur Tolerance of Bimetallic $\mathrm{PtPd} / \mathrm{Al}_{2} \mathrm{O}_{3}$ Catalysts for Hydrogenation of Tetralin by Addition of Fluorine. Catal. Lett. 2008, 122, 214-222. [CrossRef]

60. D'Ippolito, S.A.; Especel, C.; Vivier, L.; Epron, F.; Pieck, C.L. Influence of the Brønsted acidity, $\mathrm{SiO}_{2} / \mathrm{Al}_{2} \mathrm{O}_{3} \mathrm{ratio}$ and $\mathrm{Rh}-\mathrm{Pd}$ content on the ring opening: Part I. Selective ring opening of decalin. Appl. Catal. A Gen. 2014, 469, 532-540. [CrossRef]

61. Radlik, M.; Matus, K.; Karpiński, Z. n-Hexane Hydrogenolysis Behavior of Alumina-Supported Palladium-Platinum Alloys. Catal. Lett. 2019, 149, 3176-3183. [CrossRef]

62. Lee, J.-K.; Rhee, H.-K. Sulfur tolerance of zeolite beta-supported Pd-Pt catalysts for the isomerization of $n$-hexane. J. Catal. 1998, 177, 208-216. [CrossRef]

63. Ben Moussa, O.; Tinat, L.; Jin, X.; Baaziz, W.; Durupthy, O.; Sayag, C.; Blanchard, J. Heteroaggregation and Selective Deposition for the Fine Design of Nanoarchitectured Bifunctional Catalysts: Application to Hydroisomerization. ACS Catal. 2018, 8, 6071-6078. [CrossRef]

64. Talha, Z.; Bachir, C.; Ziri, S.; Bellahouel, S.; Bengueddach, A.; Villièras, F.; Pelletier, M.; Weidler, P.G.; Hamacha, R. Al-Rich Ordered Mesoporous Silica SBA-15 Materials: Synthesis, Surface Characterization and Acid Properties. Catal. Lett. 2017, 147, 2116-2126. [CrossRef]

65. Kosmulski, M. IEP as a parameter characterizing the $\mathrm{pH}$-dependent surface charging of materials other than metal oxides. Adv. Colloid Interface Sci. 2012, 171, 77-86. [CrossRef]

66. Harmel, J.; Van Der Wal, L.I.; Zečević, J.; De Jongh, P.E.; De Jong, K.P. Influence of intimacy for metal-mesoporous solid acids catalysts for n-alkanes hydro-conversion. Catal. Sci. Technol. 2020, 10, 2111-2119. [CrossRef]

67. Gopal, S.; Smirniotis, P.G. Pt/H-ZSM-12 as a catalyst for the hydroisomerization of C5-C7 n-alkanes and simultaneous saturation of benzene. Appl. Catal. A Gen. 2003, 247, 113-123. [CrossRef]

68. Poursaeidesfahani, A.; De Lange, M.F.; Khodadadian, F.; Dubbeldam, D.; Rigutto, M.; Nair, N.; Vlugt, T.J. Product shape selectivity of MFI-type, MEL-type, and BEA-type zeolites in the catalytic hydroconversion of heptane. J. Catal. 2017, 353, 54-62. [CrossRef]

69. Chao, K.-J.; Lin, C.-C.; Lin, C.-H.; Wu, H.-C.; Tseng, C.-W.; Chen, S.-H. n-Heptane hydroconversion on platinum-loaded mordenite and beta zeolites: The effect of reaction pressure. Appl. Catal. A Gen. 2000, 203, 211-220. [CrossRef]

70. Fu, J.; Feng, X.; Liu, Y.; Yang, C. Effect of pore confinement on the adsorption of mono-branched alkanes of naphtha in ZSM-5 and Y zeolites. Appl. Surf. Sci. 2017, 423, 131-138. [CrossRef]

71. Cnudde, P.; De Wispelaere, K.; Vanduyfhuys, L.; Demuynck, R.; Van Der Mynsbrugge, J.; Waroquier, M.; Van Speybroeck, V. How Chain Length and Branching Influence the Alkene Cracking Reactivity on H-ZSM-5. ACS Catal. 2018, 8, 9579-9595. [CrossRef]

72. Gao, L.; Etim, U.J.; Shi, Z.; Xing, W.; Wu, P.; Han, D.; Bai, P.; Yan, Z. Predicting Catalytic Performance of Micro-Mesoporous Pt/Beta-KIT-6 Catalyst in n-Heptane Hydroisomerization Using Indexed Isomerization Factor and Experimental Verification. Ind. Eng. Chem. Res. 2019, 58, 5146-5157. [CrossRef]

73. Martens, J.; Jacobs, P. Chapter 14 Introduction to acid catalysis with zeolites in hydrocarbon reactions. Pharmacogenetics 2001, 137, 633-671. [CrossRef]

74. Kinger, G.; Majda, D.; Vinek, H. n-Heptane hydroisomerization over Pt-containing mixtures of zeolites with inert materials. Appl. Catal. A Gen. 2002, 225, 301-312. [CrossRef]

75. Jaroszewska, K.; Fedyna, M.; Trawczyński, J. Hydroisomerization of long-chain n-alkanes over Pt/AlSBA-15+zeolite bimodal catalysts. Appl. Catal. B Environ. 2019, 255, 117756. [CrossRef]

76. Verhoef, M.J.; Kooyman, P.J.; Van Der Waal, J.C.; Rigutto, M.S.; Peters, J.A.; Van Bekkum, H. Partial Transformation of MCM-41 Material into Zeolites: Formation of Nanosized MFI Type Crystallites. Chem. Mater. 2001, 13, 683-687. [CrossRef]

77. Ibrahim, M.; Jalil, A.; Khusnun, N.; Fatah, N.; Hamid, M.; Gambo, Y.; Abdulrasheed, A.; Hassan, N. Enhanced n-hexane hydroisomerization over bicontinuous lamellar silica mordenite supported platinum (Pt/HM@KCC-1) catalyst. Int. J. Hydrog. Energy 2020, 45, 18587-18599. [CrossRef]

78. Sammoury, H.; Toufaily, J.; Cherry, K.; Hamieh, T.; Pouilloux, Y.; Pinard, L. Impact of desilication of *BEA zeolites on the catalytic performance in hydroisomerization of n-C 10. Appl. Catal. A Gen. 2018, 551, 1-12. [CrossRef]

79. Roldán, R.; Romero, F.J.; Jiménez-Sanchidrián, C.; Marinas, J.M.; Gómez, J.P. Influence of acidity and pore geometry on the product distribution in the hydroisomerization of light paraffins on zeolites. Appl. Catal. A Gen. 2005, 288, 104-115. [CrossRef]

80. Bauer, F.; Ficht, K.; Bertmer, M.; Einicke, W.-D.; Kuchling, T.; Gläser, R. Hydroisomerization of long-chain paraffins over nano-sized bimetallic Pt-Pd/H-beta catalysts. Catal. Sci. Technol. 2014, 4, 4045-4054. [CrossRef]

81. Niquille-Röthlisberger, A.; Prins, R. Hydrodesulfurization of 4,6-dimethyldibenzothiophene over Pt, Pd, and Pt-Pd catalysts supported on amorphous silica-alumina. Catal. Today 2007, 123, 198-207. [CrossRef] 
82. Yu, Y.; Fonfé, B.; Jentys, A.; Haller, G.L.; Van Veen, J.R.; Gutiérrez, O.Y.; Lercher, J.A.; Tinoco, O.G. Bimetallic Pt-Pd/silica-alumina hydrotreating catalysts. Part II: Structure-activity correlations in the hydrogenation of tetralin in the presence of dibenzothiophene and quinoline. J. Catal. 2012, 292, 13-25. [CrossRef]

83. Lin, S.-D.; Vannice, M. Supported platinum, Studies in Surface Science and Catalysis. In Proceedings of the 10th International Congress on Catalusis, Budapest, Hungary, 19-24 July 2021; Volume 75, pp. 861-874.

84. Chupin, J.; Gnep, N.; Lacombe, S.; Guisnet, M. Influence of the metal and of the support on the activity and stability of bifunctional catalysts for toluene hydrogenation. Appl. Catal. A Gen. 2001, 206, 43-56. [CrossRef]

85. Blomsma, E.; Martens, J.; Jacobs, P. Isomerization and Hydrocracking of Heptane over Bimetallic Bifunctional PtPd/H-Beta and PtPd/USY Zeolite Catalysts. J. Catal. 1997, 165, 241-248. [CrossRef]

86. Navarro, R.; Pawelec, B.; Trejo, J.; Mariscal, R.; Fierro, J. Hydrogenation of Aromatics on Sulfur-Resistant PtPd Bimetallic Catalysts. J. Catal. 2000, 189, 184-194. [CrossRef]

87. Roldan, R.; Beale, A.; Sanchezsanchez, M.; Romerosalguero, F.; Jimenezsanchidrian, C.; Gomez, J.; Sankar, G. Effect of the impregnation order on the nature of metal particles of bi-functional $\mathrm{Pt} / \mathrm{Pd}$-supported zeolite Beta materials and on their catalytic activity for the hydroisomerization of alkanes. J. Catal. 2008, 254, 12-26. [CrossRef]

88. Nikolaou, N.; Papadopoulos, C.; Gaglias, I.; Pitarakis, K. A new non-linear calculation method of isomerisation gasoline research octane number based on gas chromatographic data. Fuel 2004, 83, 517-523. [CrossRef]

89. Hasan, M.; Mohamed, A.; Al-Kandari, H. Semi-industrial studies of Tungsten-based catalyst for hydroisomerization/hydrocracking of n-hexane and n-heptane. Mol. Catal. 2018, 452, 1-10. [CrossRef]

90. Vinu, A.; Murugesan, V.; Böhlmann, A.W.; Hartmannt, M. An Optimized Procedure for the Synthesis of AlSBA-15 with Large Pore Diameter and High Aluminum Content. J. Phys. Chem. B 2004, 108, 11496-11505. [CrossRef]

91. Fagherazzi, G.; Canton, P.; Riello, P.; Pernicone, N.; Pinna, F.; Battagliarin, M. Nanostructural Features of Pd/C Catalysts Investigated by Physical Methods: A Reference for Chemisorption Analysis. Langmuir 2000, 16, 4539-4546. [CrossRef] 